Discussion Paper No. 1009

\title{
PRODUCT DIFFERENTIATION \\ AND ENTRY TIMING IN A CONTINUOUS-TIME SPATIAL COMPETITION MODEL WITH VERTICAL RELATIONS
}

Takeshi Ebina

Noriaki Matsushima

August 2017

The Institute of Social and Economic Research Osaka University

6-1 Mihogaoka, Ibaraki, Osaka 567-0047, Japan 


\title{
Product differentiation and entry timing in a continuous-time spatial competition model with vertical relations*
}

\author{
Takeshi Ebina ${ }^{\dagger}$ \\ Institute of Social Sciences, Shinshu University \\ Noriaki Matsushima $a^{\ddagger}$ \\ Institute of Social and Economic Research, Osaka University
}

August 17, 2017

\begin{abstract}
We study the entry timing and location decisions of two exclusive buyer-supplier relationships in a continuous-time spatial competition model. In each relationship, the firms determine their entry timing and location, and negotiate a wholesale price through Nash bargaining. Then, the downstream firm immediately determines its retail price. Our findings are as follows. Ordinarily, if the supplier of the first entrant (called the leader pair) has strong bargaining power, the equilibrium location of the leader will be closer to the center, inducing a delay in entry by the second entrant (called the follower pair). This delay implies the stronger bargaining power of the supplier in the leader pair can also benefit the buyer of the pair. The location of the leader pair can change non-monotonically with an increase in the supplier's bargaining power, which has a substantial impact on the entry timing of the follower pair. However, the greater the bargaining power of the supplier in the follower pair, the closer the leader pair will be to the edge. This implies that having greater bargaining power will enhance the profitability of the supplier in the follower pair.
\end{abstract}

Keywords: Entry timing; Hotelling model; Vertical relations; Continuous-time model; Nash bargaining

JEL codes: C71, L11, L13, R32.

*The authors gratefully acknowledge financial support from a Grant-in-Aid for Basic Research (15H03349, 15H05728, 17H00984) and Young Scientists (15K17047) from the Japan Society for the Promotion of Science and the MEXT. We also thank seminar participants at Shinshu University for helpful comments. Needless to say, we are responsible for any remaining errors.

${ }^{\dagger}$ Institute of Social Sciences, Shinshu University, 3-1-1, Asahi, Matsumoto, Nagano, Japan. Phone: (81)4-8021-7663. Fax: (81)-4-8021-7654. E-mail: ebina@shinshu-u.ac.jp

${ }^{\ddagger}$ Institute of Social and Economic Research, Osaka University, Mihogaoka 6-1, Ibaraki, Osaka, Japan. Phone: (81)-6-6879-8571. Fax: (81)-6-6879-8583. E-mail: nmatsush@iser.osaka-u.ac.jp 


\section{Introduction}

When firms face situations in which markets are growing, as in new product markets and newly developed cities, the timing of entry and product positioning are important strategic issues. For instance, mobile phone services have been growing in most countries since they were first introduced in 1981 in Scandinavia; and for some countries, the penetration levels of mobile phones have already reached more than 100\% (Peres et al., 2010). In addition, "the massive penetration of mobile telephony is not exceptional - many commonly used products and services, such as DVDs, personal computers, digital cameras, online banking, and the Internet, were unknown to consumers three decades ago" (Peres et al., 2010, p.91). Naturally, companies in these industries consider product positions and entry decisions when they launch new products. In addition, in the context of retailing, many leading retailers in developed countries have launched stores in countries that are in different stages of economic development (Reinartz et al., 2011). In particular, in emerging countries, including the BRIC countries, Mexico, Poland, and South Africa, "the total population [...] considerably exceeds the population of developed countries, making these regions particularly attractive for mature market-based retailers and retailing innovations that are responsive to the distinctive characteristics of these markets" (Reinartz et al., 2011, p.S55). In this context, the profitability of these retailers is significantly influenced by geographical distances and the location choices of rivals in each region. ${ }^{1}$

Manufacturers/franchisors usually sell their products through independent downstream representatives/franchisees; that is, vertical relations are often observed in contexts such as

\footnotetext{
${ }^{1}$ Several empirical studies show that geographical proximity influences the pricing decisions of retailers (Bronnenberg and Mahajan, 2001; Zhu and Singh, 2009; Cleeren et al., 2010; Orhun, 2013). In addition, many studies have empirically investigated how positioning strategies influence firm profitability (e.g., Thomadsen, 2007; Draganska et al., 2009; Hwang et al., 2010).
} 
manufacturers and retail representatives, franchisors and franchisees, and so on. ${ }^{2}$ In this context, several papers emphasize that large nationwide retailers tend to have strong bargaining power over their upstream trading partners, enabling them to be highly competitive in retail markets (Geylani et al., 2007; Inderst and Shaffer, 2007, 2009). In other words, strong bargaining power over trading partners is recognized as a source of competitiveness. In summary, when examining the growth of markets and vertical relations, we need to consider firms' product positioning and entry timing.

In line with the literature on positioning strategies and product differentiation (in marketing, Wernerfelt, 1986; Hauser, 1988; Moorthy, 1988; Desai, 2001; Kuksov, 2004; Sajeesh and Raju, 2010, among others; in economics, d'Aspremont et al., 1979; Tabuchi and Thisse, 1995; Kim and Serfes, 2006; Matsumura and Matsushima, 2009; Sajeesh, 2016, among others), we investigate how market growth influences product positioning/differentiation in a continuous-time spatial competition model with entry timing decisions and vertical relations. In the context of economics, marketing, and related fields, with the exception of Lambertini (2002), Ebina et al. (2015), and Ebina et al. (2017), ${ }^{3}$ no studies have investigated product positioning strategies using continuous-time Hotelling-type spatial competition models with market growth and entry timing. However, several related studies do use Hotelling models to investigate the sequential entry of firms (e.g., Götz, 2005, Loertscher and Muehlheusser, 2011) and buyer-supplier relations (e.g., Brekke and Straume, 2004; Matsushima, 2004, 2009; Erkal, 2007, Geylani et al., 2007; Liu and Tyagi, 2011; Matsushima and Miyaoka, 2015; Matsushima and Pan, 2016).

\footnotetext{
2 Several recent studies investigate the objectives of retailers and their increased power in channels (Dobson and Waterson, 1997; Chen, 2003; Raju and Zhang, 2005; Dukes et al., 2006). In addition, in the context of outsourcing by downstream firms, several studies investigate the interactions between sourcing modes and profitability (Liu and Tyagi, 2011; Matsushima and Pan, 2016).

3 Using a non-spatial dynamic duopoly model with exclusive vertical relations, Alipranti et al. (2015) investigate the timing of technology adoption and contract types (linear pricing and two-part tariffs).
} 
This study substantially extends the work of Ebina et al. (2015) by incorporating two pairs of an upstream supplier/franchisor and a downstream buyer/franchisee in their model. Ebina et al. (2015) discuss endogenous decisions on locations and entry-timing in a Hotelling duopoly model with market growth. ${ }^{4}$ Here, we investigate how upstream suppliers' bargaining power over downstream buyers influences the locations of the two pairs, the timing of entry by the follower pair, and the value of each firm.

Our findings are as follows. Ordinarily, if the supplier in a leader pair has stronger bargaining power (denoted as $\beta_{1}$ ), this induces the pair to locate closer to the center, and the follower pair to enter the market later. This implies that the stronger bargaining power of the supplier can also benefit the downstream buyer. That is, it might be better for a downstream buyer to weaken its bargaining position over its trading supplier. In reality, there are several examples in which buyers encourage suppliers to organize collective associations, even though this would weaken the buyers' bargaining power (e.g., the Carrefour case in Raynaud et al. (2009, pp.851-2)). In addition, there can be a non-monotonic relation between $\beta_{1}$ and the leader pair's location. More specifically, the equilibrium location of the leader pair can jump significantly with an increase in $\beta_{1}$, which delays the entry timing of the follower pair substantially. On the other hand, an increase in the bargaining power of the supplier in the follower pair induces the leader pair to locate closer to the edge, which facilitates earlier entry by the follower pair. This implies that when an upstream manufacturer tries to enter a newly growing market with its downstream representative, maintaining its bargaining power over its representative is quite important.

The remainder of the paper organized as follows. Section 2 provides the model setting, and Section 3 describes the results of the model. Section 4 provides numerical analyses of

\footnotetext{
${ }^{4}$ Ebina et al. (2017) provide another major extension to the work of Ebina et al. (2015) by incorporating market-size uncertainty with Brownian motion in the setting of Ebina et al. (2015). However, the direction of this extension is quite different to ours.
} 
the model. Then, Section 5 discusses the relation between our study and that of Ebina et al. (2015), as well as the case in which the bargaining power in each pair is symmetric. Section 6 concludes the paper, and Section 7 is the Appendix.

\section{Model}

There are two competing upstream firms $U_{1}$ and $U_{2}$. Upstream firm $U_{i}$ forms a vertical group with a downstream firm $D_{i}(i=1,2)$. Thus, there are four firms: two upstream firms $U_{1}$ and $U_{2}$, and two downstream firms $D_{1}$ and $D_{2}$. In group $i, U_{i}$ and $D_{i}$ negotiate a wholesale price $w_{i t}$, paid from $D_{i}$ to $U_{i}$ at time $t$. The negotiation is based on the standard Nash bargaining (Muthoo, 1999). Here, $\beta_{i} \in[0,1]$ denotes the bargaining power of $U_{i}$.

There is a mass of consumers uniformly distributed on the line segment $[0,1]$. The size of this mass is $\exp (\alpha t)$, where $\alpha$ is the growth rate of the size (market size). The utility of the consumer at point $x \in[0,1]$ at time $t \in[0, \infty)$ is given by

$$
u_{t}\left(x ; x_{1}, x_{2}, p_{1 t}, p_{2 t}\right)= \begin{cases}\bar{u}-p_{1 t}-c\left(x_{1}-x\right)^{2} & \text { if purchased from firm } D_{1}, \\ \bar{u}-p_{2 t}-c\left(x_{2}-x\right)^{2} & \text { if purchased from firm } D_{2}, \\ 0 & \text { otherwise }\end{cases}
$$

where $\bar{u}>0$ denotes the gross surplus that a consumer at point $x \in[0,1]$ enjoys from purchasing the good, $p_{i t}$ is the price of $D_{i}$ at time $t$, and $c>0$ is a parameter describing the level of transportation cost or product differentiation. ${ }^{5}$ From (1), the consumer who is indifferent between purchasing from $D_{1}$ and $D_{2}$ is $\bar{x}=\left[p_{2 t}-p_{1 t}+c\left(x_{2}^{2}-x_{1}^{2}\right)\right] /\left[2 c\left(x_{2}-x_{1}\right)\right]$. We assume that $\bar{u}$ is so large that all consumers purchase one unit of the product from one of the firms. More specifically, we assume the following inequality:

Assumption $1 \bar{u}>m+3 c$.

\footnotetext{
${ }^{5}$ We consider a situation in which the population of consumers at time $t$ is $N \exp (\alpha t)$, which we normalize to $N=1$. Therefore, our interpretation is that $\alpha$ corresponds to the increasing rate of population and is called the market growth rate. This interpretation is the same as that of Ebina et al. (2015). The validity of this assumption under the Hotelling model is explained in Footnote 7 of their study.
} 
The sequence of entries is as follows: Group 1 is the leader pair, who enter immediately at $T_{1}=0$. Group 2 is the follower pair, who enter at time $T_{2} \in(0, \infty)$, which is determined endogenously later. Firm $D_{i}$ incurs an entry cost $F_{i}\left(T_{i}\right)$, which is evaluated at time 0 and decreasing in $T_{i}$. The game analyzed is an infinite-horizon game.

In group $1, U_{1}$ determines the group's location $x_{1}$ at time $T_{1}=0$. We assume (without loss of generality) that $x_{1} \leq 1 / 2$ holds in equilibrium. After entry, $w_{1 t}$ is determined through Nash bargaining between $D_{1}$ and $U_{1}$, and then $D_{1}$ sets its price $p_{1 t}$ at $t \in[\tau, \tau+d \tau)$. Group 1 becomes the monopoly, and can repeat the bargaining and pricing process whenever group 2 is out of the market.

In group $2, U_{2}$ offers a contract $\left(T_{2}, x_{2}\right)$ to $D_{2}$ unilaterally. This implies that $U_{2}$ is in a strong position over $D_{2}$ only in terms of the entry timing. ${ }^{6}$ Note that we assume that the follower group enters if and only if entry is just acceptable for $D_{2}$, although we can derive similar results under a different criterion for the entry decision, which is assumed in Ebina et al. (2015). ${ }^{7}$

After entry, competition between the groups occurs. Here, $w_{1 t}$ and $w_{2 t}$ are determined simultaneously through Nash bargaining. Observing the negotiation outcomes, $D_{1}$ and $D_{2}$ simultaneously set their prices $p_{1 t}$ and $p_{2 t}$ at $t \in[\tau, \tau+d \tau)$.

The total profits of the upstream $\left(V_{1}\right.$ and $\left.V_{2}\right)$ and downstream $\left(v_{1}\right.$ and $\left.v_{2}\right)$ firms of groups 1 and 2 (the leader and the follower pairs, respectively) are given by

$$
V_{1}\left(T_{2}, x_{1}, x_{2}, p_{1 t}, p_{2 t}, w_{1 t}\right)=\int_{0}^{T_{2}} \int_{0}^{1}\left[w_{1 t}-m\right] e^{-(r-\alpha) t} d x d t+\int_{T_{2}}^{\infty} \int_{0}^{\bar{x}}\left[w_{1 t}-m\right] e^{-(r-\alpha) t} d x d t
$$

\footnotetext{
${ }^{6}$ This assumption is suitable to situations in which $U_{2}$ is able to select one of many potential downstream agents. However, $U_{2}$ then faces a lock-in after signing the contract with $D_{2}$, owing to the necessary coordination with $D_{2}$ for production, giving some bargaining power to $D_{2}$.

${ }^{7}$ Other than incorporating a negotiation in each group and a unilateral offer of the contract $\left(T_{2}, x_{2}\right)$ by $U_{2}$ to $D_{2}$, the basic timing structure is the same as that of Ebina et al. (2015). However, our main results hold even under a different criterion for the entry decision. We discuss this point in Section 5.1.
} 


$$
\begin{aligned}
v_{1}\left(T_{2}, x_{1}, x_{2}, p_{1 t}, p_{2 t}, w_{1 t}\right)=\int_{0}^{T_{2}} \int_{0}^{1}\left[p_{1 t}-w_{1 t}\right] & e^{-(r-\alpha) t} d x d t \\
& +\int_{T_{2}}^{\infty} \int_{0}^{\bar{x}}\left[p_{1 t}-w_{1 t}\right] e^{-(r-\alpha) t} d x d t-F_{1}(0),
\end{aligned}
$$

and

$$
\begin{gathered}
V_{2}\left(T_{2}, x_{1}, x_{2}, p_{1 t}, p_{2 t}, w_{2 t}\right)=\int_{T_{2}}^{\infty} \int_{\bar{x}}^{1}\left[w_{2 t}-m\right] e^{-(r-\alpha) t} d x d t \\
v_{2}\left(T_{2}, x_{1}, x_{2}, p_{1 t}, p_{2 t}, w_{2 t}\right)=\int_{T_{2}}^{\infty} \int_{\bar{x}}^{1}\left[p_{2 t}\left(x ; x_{1}, x_{2}, p_{1 t}\right)-w_{2 t}\right] e^{-(r-\alpha) t} d x d t-F_{2}\left(T_{2}\right),
\end{gathered}
$$

where $m$ and $r$ denote the marginal cost of each upstream firm and the interest rate, respectively. We assume that $r>\alpha$ to ensure that the follower enters within a finite time frame. ${ }^{8}$

With respect to the bargaining power of group 1, we make the following assumption:

Assumption $2 \beta_{1} \in(0,(\bar{u}-m-3 c) /(\bar{u}-m-c))$.

This assumption ensures that the monopoly outcome of group 1 at each $t \in\left[0, T_{2}\right)$ has an interior solution. With respect to $F_{2}$, we also make the following assumption:

Assumption 3 (i) $F_{i}\left(T_{i}\right)=F_{i} \exp \left(-r T_{i}\right)$. (ii) $F_{2}>\left[c\left(2+\beta_{1}\right)^{2}\left(2-\beta_{2}\right)^{2}\right] /\left[(r-\alpha)\left(4-\beta_{1} \beta_{2}\right)^{2}\right]$.

Assumption 3 (i) is made to explicitly obtain an outcome for the subgame perfect Nash equilibrium, and is the same as that in Ebina et al. (2015). ${ }^{9}$ Assumption 3 (ii) ensures that

\footnotetext{
${ }^{8}$ If $r \leq \alpha$, the integral of Equation (4) could be made indefinitely larger by choosing a larger time $T_{2}$. Thus, waiting longer would always be a better strategy, and the optimum would not exist.

${ }^{9}$ We adopt a setting where $\alpha$ represents the increasing rate of population, because we consider that this interpretation is more natural and valid under a Hotelling location model. However, many studies consider that $\alpha$ represents a cost-reducing rate when firms adopt a new technology, and assume $F_{i}=\exp \left(-(r-\alpha) T_{i}\right)$. If we modify our interpretation (growing market) to that of technology improvement, our main results do not change. Here, we can make a similar argument to that explained in the Appendix of Ebina et al. (2015, p.912).
} 
group 2 enters at a positive time $T_{2}(>0)$, and that sequential entry always occurs. This allows us to avoid simultaneous entry at time 0 and to focus on sequential entry. ${ }^{10}$

The game proceeds as follows: At $T_{1}=0, U_{1}$ in group 1 determines the location of group $1, x_{1}$, in order to maximize its own total profit. Observing $x_{1}$, and to maximize its own total profit, $U_{2}$ offers contract $\left(T_{2}, x_{2}\right)$ to $D_{2}$. At each instance $t \in[\tau, \tau+d \tau)$, and knowing whether group 2 is active, group $i$ determines $w_{i t}$ through Nash bargaining between $U_{i}$ and $D_{i}$, if the group is active. Finally, $D_{i}$ sets its price $p_{i t}$.

\section{Equilibrium}

We derive the price outcome in the subgame perfect Nash equilibrium in Section 3.1, the timing and the location outcomes of group 2 in Section 3.2, the location outcome of group 1 in Section 3.3, and the outcomes of the subgame perfect Nash equilibrium in Section 3.4.

\subsection{Price}

First, we consider the problem of prices at each $t \in[\tau, \tau+d \tau)$, before and after the entry of group 2, given $x_{1}, x_{2}$, and $T_{2}$. Then, we derive the local profits of $U_{1}, U_{2}, D_{1}$, and $D_{2}$ at each $t \in[\tau, \tau+d \tau)$. Next, we provide the relations between the local profits and the bargaining power parameters, $\beta_{1}$ and $\beta_{2}$, in Remarks 1 to 3 . The three remarks will be helpful to understand the intuition behind our main results shown in this and the next sections.

First, we consider the subgame after group 2 enters, that is, the subgame at $t \in\left[T_{2}, \infty\right)$.

\footnotetext{
${ }^{10}$ If simultaneous entry occurs, our model reverts to the standard location-price model with a vertical relationship. Then, an equilibrium location pattern simply becomes the maximum differentiation. For more detail, see Brekke and Straume (2004).
} 
Given $w_{1 t}$ and $w_{2 t}$ at $t \in\left[T_{2}, \infty\right)$, the profits of the downstream firms are

$$
\begin{aligned}
& \pi_{1 t}\left(p_{1 t}, p_{2 t} ; x_{1}, x_{2}, w_{1 t}\right)=\left(p_{1 t}-w_{1 t}\right) \bar{x} \\
& \pi_{2 t}\left(p_{1 t}, p_{2 t} ; x_{1}, x_{2}, w_{1 t}\right)=\left(p_{2 t}-w_{2 t}\right)(1-\bar{x}) .
\end{aligned}
$$

Solving the first-order conditions of the downstream firms, we have the following instantaneous prices:

$$
\begin{aligned}
& p_{1 t}\left(w_{1 t}, w_{2 t} ; x_{1}, x_{2}\right)=\frac{2 w_{1 t}+w_{2 t}+c\left(x_{2}-x_{1}\right)\left(2+x_{1}+x_{2}\right)}{3}, \\
& p_{2 t}\left(w_{1 t}, w_{2 t} ; x_{1}, x_{2}\right)=\frac{w_{1 t}+2 w_{2 t}+c\left(x_{2}-x_{1}\right)\left(4-x_{1}-x_{2}\right)}{3} .
\end{aligned}
$$

Substituting these into the profits of the firms and $\bar{x}$, we have

$$
\begin{aligned}
\pi_{1 t}\left(w_{1 t}, w_{2 t}, x_{1}, x_{2}\right) & =\frac{\left(w_{2 t}-w_{1 t}+c\left(x_{2}-x_{1}\right)\left(2+x_{1}+x_{2}\right)\right)^{2}}{18 c\left(x_{2}-x_{1}\right)} \\
\pi_{2 t}\left(w_{1 t}, w_{2 t}, x_{1}, x_{2}\right) & =\frac{\left(w_{1 t}-w_{2 t}+c\left(x_{2}-x_{1}\right)\left(4-x_{1}-x_{2}\right)\right)^{2}}{18 c\left(x_{2}-x_{1}\right)} \\
\Pi_{1 t}\left(w_{1 t}, w_{2 t}, x_{1}, x_{2}\right) & =\frac{\left(w_{1 t}-m\right)\left(w_{2 t}-w_{1 t}+c\left(x_{2}-x_{1}\right)\left(2+x_{1}+x_{2}\right)\right)}{6 c\left(x_{2}-x_{1}\right)} \\
\Pi_{2 t}\left(w_{1 t}, w_{2 t}, x_{1}, x_{2}\right) & =\frac{\left(w_{2 t}-m\right)\left(w_{1 t}-w_{2 t}+c\left(x_{2}-x_{1}\right)\left(4-x_{1}-x_{2}\right)\right)}{6 c\left(x_{2}-x_{1}\right)}, \\
\bar{x}\left(w_{1 t}, w_{2 t}, x_{1}, x_{2}\right) & =\frac{2+x_{1}+x_{2}}{6}+\frac{w_{2 t}-w_{1 t}}{6 c\left(x_{2}-x_{1}\right)} .
\end{aligned}
$$

Next, we consider the bargaining problems in the vertical groups. Substituting the profits into the objective functions of the bargaining problems in the vertical chains, $\Omega_{1 t}$ and $\Omega_{2 t}$, we have

$$
\begin{aligned}
& \Omega_{1 t}\left(w_{1 t}, w_{2 t} ; x_{1}, x_{2}\right)=\left[\Pi_{1 t}\left(w_{1 t}, w_{2 t}, x_{1}, x_{2}\right)\right]^{\beta_{1}}\left[\pi_{1 t}\left(w_{1 t}, w_{2 t}, x_{1}, x_{2}\right)\right]^{1-\beta_{1}}, \\
& \Omega_{2 t}\left(w_{1 t}, w_{2 t} ; x_{1}, x_{2}\right)=\left[\Pi_{2 t}\left(w_{1 t}, w_{2 t}, x_{1}, x_{2}\right)\right]^{\beta_{2}}\left[\pi_{2 t}\left(w_{1 t}, w_{2 t}, x_{1}, x_{2}\right)\right]^{1-\beta_{2}} .
\end{aligned}
$$

Each vertical group $i$ determines $w_{i}$ to maximize $\Omega_{i t}$. Solving the maximization problems of 
the groups, we have

$$
\begin{aligned}
& w_{1 t}\left(x_{1}, x_{2}\right)=m+\frac{c \beta_{1}\left(x_{2}-x_{1}\right)\left[2\left(2+x_{1}+x_{2}\right)+\left(4-x_{1}-x_{2}\right) \beta_{2}\right]}{4-\beta_{1} \beta_{2}}\left(\equiv w_{1}^{D}\left(x_{1}, x_{2}\right)\right), \\
& w_{2 t}\left(x_{1}, x_{2}\right)=m+\frac{c \beta_{2}\left(x_{2}-x_{1}\right)\left[2\left(4-x_{1}-x_{2}\right)+\left(2+x_{1}+x_{2}\right) \beta_{1}\right]}{4-\beta_{1} \beta_{2}}\left(\equiv w_{2}^{D}\left(x_{1}, x_{2}\right)\right) .
\end{aligned}
$$

Here, $w_{i t}\left(x_{1}, x_{2}\right)$ monotonically increases with $\beta_{i}$ for any $\beta_{i}(\in(0,1))$.

Substituting these wholesale prices into Equations (6) and (7), we have

$$
\begin{aligned}
& p_{1 t}\left(x_{1}, x_{2}\right)=m+\frac{2 c\left(1+\beta_{1}\right)\left(x_{2}-x_{1}\right)\left[2\left(2+x_{1}+x_{2}\right)+\left(4-x_{1}-x_{2}\right) \beta_{2}\right]}{3\left(4-\beta_{1} \beta_{2}\right)}\left(\equiv p_{1}^{D}\left(x_{1}, x_{2}\right)\right), \\
& p_{2 t}\left(x_{1}, x_{2}\right)=m+\frac{2 c\left(1+\beta_{2}\right)\left(x_{2}-x_{1}\right)\left[2\left(4-x_{1}-x_{2}\right)+\left(2+x_{1}+x_{2}\right) \beta_{1}\right]}{3\left(4-\beta_{1} \beta_{2}\right)}\left(\equiv p_{2}^{D}\left(x_{1}, x_{2}\right)\right) .
\end{aligned}
$$

In this case, $p_{i t}\left(x_{1}, x_{2}\right)$ monotonically increases with $\beta_{i}$ for any $\beta_{i}(\in(0,1))$.

The indifferent consumer is

$$
\bar{x}\left(x_{1}, x_{2}\right)=\frac{\left(2-\beta_{1}\right)\left[2\left(2+x_{1}+x_{2}\right)+\left(4-x_{1}-x_{2}\right) \beta_{2}\right]}{6\left(4-\beta_{1} \beta_{2}\right)},
$$

where $\bar{x}\left(x_{1}, x_{2}\right)$ monotonically decreases (resp. increases) with $\beta_{1}$ (resp. $\beta_{2}$ ) for any $\beta_{1}(\in$ $(0,(\bar{u}-m-3 c) /(\bar{u}-m-c)))\left(\operatorname{resp} . \beta_{2}(\in(0,1))\right)$.

Next, we consider the subgame before group 2 enters, that is, the subgame at $t \in\left[0, T_{2}\right)$. Since $D_{1}$ is the monopolist in the market, it chooses $p_{1 t}=\bar{u}-c\left(1-x_{1}\right)^{2}$ if $w_{1 t}$ is not sufficiently large. ${ }^{11}$ The objective function of the bargaining problem in the vertical chain of group 1 is

$$
\Pi_{1 t}^{\beta_{1}} \times \pi_{1 t}^{1-\beta_{1}}=\left(w_{1 t}-m\right)^{\beta}\left(\bar{u}-c\left(1-x_{1}\right)^{2}-w_{1 t}\right)^{1-\beta} .
$$

The wholesale price is

$$
w_{1}^{M}\left(x_{1}\right)=\left[\bar{u}-c\left(1-x_{1}\right)^{2}\right] \beta_{1}+m\left(1-\beta_{1}\right) .
$$

Thus, we have the following lemma.

\footnotetext{
${ }^{11}$ In the Appendix, we discuss the possibility that the market demand is partially covered by the monopolist.
} 
Lemma 1 The prices set by the upstream and the downstream firms are

$$
\begin{aligned}
& \tilde{w}_{1 t}\left(x_{1}, x_{2}\right)= \begin{cases}{\left[\bar{u}-c\left(1-x_{1}\right)^{2}\right] \beta_{1}+m\left(1-\beta_{1}\right)} & t \in\left[0, T_{2}\right), \\
m+\frac{c \beta_{1}\left(x_{2}-x_{1}\right)\left[2\left(2+x_{1}+x_{2}\right)+\left(4-x_{1}-x_{2}\right) \beta_{2}\right]}{4-\beta_{1} \beta_{2}} & t \in\left[T_{2}, \infty\right),\end{cases} \\
& \tilde{p}_{1 t}\left(x_{1}, x_{2}\right)= \begin{cases}\bar{u}-c\left(1-x_{1}\right)^{2} & t \in\left[0, T_{2}\right), \\
m+\frac{2 c\left(1+\beta_{1}\right)\left(x_{2}-x_{1}\right)\left[2\left(2+x_{1}+x_{2}\right)+\left(4-x_{1}-x_{2}\right) \beta_{2}\right]}{3\left(4-\beta_{1} \beta_{2}\right)} & t \in\left[T_{2}, \infty\right),\end{cases} \\
& \tilde{w}_{2 t}\left(x_{1}, x_{2}\right)=m+\frac{c \beta_{2}\left(x_{2}-x_{1}\right)\left[2\left(4-x_{1}-x_{2}\right)+\left(2+x_{1}+x_{2}\right) \beta_{1}\right]}{4-\beta_{1} \beta_{2}} t \in\left[T_{2}, \infty\right), \\
& \tilde{p}_{2 t}\left(x_{1}, x_{2}\right)=m+\frac{2 c\left(1+\beta_{2}\right)\left(x_{2}-x_{1}\right)\left[2\left(4-x_{1}-x_{2}\right)+\left(2+x_{1}+x_{2}\right) \beta_{1}\right]}{3\left(4-\beta_{1} \beta_{2}\right)} t \in\left[T_{2}, \infty\right) .
\end{aligned}
$$

The instantaneous profit flows of the two groups are

$$
\begin{aligned}
& \Pi_{1 t}\left(x_{1}, x_{2}\right)= \begin{cases}\Pi_{1}^{M}\left(x_{1}\right) \equiv \int_{0}^{1}\left[w_{1}^{M}\left(x_{1}\right)-m\right] d x=\left[\bar{u}-c\left(1-x_{1}\right)^{2}-m\right] \beta_{1} & t \in\left[0, T_{2}\right), \\
\Pi_{1}^{D}\left(x_{1}, x_{2}\right) \equiv \int_{0}^{\bar{x}}\left[w_{1}^{D}\left(x_{1}, x_{2}\right)-m\right] d x & \\
\quad=\frac{c \beta_{1}\left(2-\beta_{1}\right)\left(x_{2}-x_{1}\right)\left[2\left(2+x_{1}+x_{2}\right)+\left(4-x_{1}-x_{2}\right) \beta_{2}\right]^{2}}{6\left(4-\beta_{1} \beta_{2}\right)^{2}} & t \in\left[T_{2}, \infty\right),\end{cases} \\
& \pi_{1 t}\left(x_{1}, x_{2}\right)= \begin{cases}\pi_{1}^{M}\left(x_{1}\right) \equiv \int_{0}^{1}\left[p_{1}^{M}\left(x_{1}\right)-w_{1}^{M}\left(x_{1}\right)\right] d x=\left[\bar{u}-c\left(1-x_{1}\right)^{2}-m\right]\left(1-\beta_{1}\right) & t \in\left[0, T_{2}\right), \\
\pi_{1}^{D}\left(x_{1}, x_{2}\right) \equiv \int_{0}^{\bar{x}}\left[p_{1}^{D}\left(x_{1}, x_{2}\right)-w_{1}^{D}\left(x_{1}, x_{2}\right)\right] d x & \\
\quad=\frac{c\left(2-\beta_{1}\right)^{2}\left(x_{2}-x_{1}\right)\left[2\left(2+x_{1}+x_{2}\right)+\left(4-x_{1}-x_{2}\right) \beta_{2}\right]^{2}}{18\left(4-\beta_{1} \beta_{2}\right)^{2}} & t \in\left[T_{2}, \infty\right),\end{cases} \\
& \Pi_{2 t}\left(x_{1}, x_{2}\right)= \begin{cases}0 & t \in\left[0, T_{2}\right), \\
\Pi_{2}^{D}\left(x_{1}, x_{2}\right)=\int_{\bar{x}}^{1}\left[w_{2}^{D}\left(x_{1}, x_{2}\right)-m\right] d x & \\
=\frac{c\left(2-\beta_{2}\right) \beta_{2}\left(x_{2}-x_{1}\right)\left[2\left(4-x_{1}-x_{2}\right)+\left(2+x_{1}+x_{2}\right) \beta_{1}\right]^{2}}{6\left(4-\beta_{1} \beta_{2}\right)^{2}} & t \in\left[T_{2}, \infty\right),\end{cases} \\
& \pi_{2 t}\left(x_{1}, x_{2}\right)= \begin{cases}0 & t \in\left[0, T_{2}\right), \\
\pi_{2}^{D}\left(x_{1}, x_{2}\right)=\int_{\bar{x}}^{1}\left[p_{2}^{D}\left(x_{1}, x_{2}\right)-w_{2}^{D}\left(x_{1}, x_{2}\right)\right] d x & \\
=\frac{c\left(2-\beta_{2}\right)^{2}\left(x_{2}-x_{1}\right)\left[2\left(4-x_{1}-x_{2}\right)+\left(2+x_{1}+x_{2}\right) \beta_{1}\right]^{2}}{18\left(4-\beta_{1} \beta_{2}\right)^{2}} & t \in\left[T_{2}, \infty\right) .\end{cases}
\end{aligned}
$$

Second, before presenting the nature of the locations and the bargaining power parameters, we briefly summarize the effects of bargaining power on the ratio of the monopoly and the duopoly profits for $U_{1}$, namely $\Pi_{1}^{M}\left(x_{1}\right) / \Pi_{1}^{D}\left(x_{1}\right)$, which directly influences the location decision of $U_{1}$. 
Lemma 2 (i) If $\beta_{1}$ increases, the ratio of the monopoly and the duopoly profits, $\Pi_{1}^{M}\left(x_{1}\right) / \Pi_{1}^{D}\left(x_{1}\right)$, increases.

(ii) If $\beta_{2}$ increases, the ratio of the monopoly and the duopoly profits, $\Pi_{1}^{M}\left(x_{1}\right) / \Pi_{1}^{D}\left(x_{1}\right)$, decreases.

As $\beta_{1}$ increases, the competitiveness of $D_{1}$ weakens owing to an increase in $w_{1 t}$ in the duopoly, although this does not matter in the monopoly. This implies that the relative importance of the monopoly profit increases as $\beta_{1}$ increases. In addition, as $\beta_{2}$ increases, the competitiveness of $D_{1}$ strengthens owing to the increase in $w_{2 t}$ in the duopoly, although this does not matter in the monopoly. This implies that the relative importance of the duopoly profit for group 1 increases as $\beta_{2}$ increases.

Before considering the problem of each group's entry timing, we summarize three properties with respect to instantaneous profits. These properties are discussed and utilized in Subsection 4.2.

Remark 1 The instantaneous profit of a firm in a vertical chain is completely correlated with that of another firm in the sense that the locations, $x_{1}$ and $x_{2}$, influence the profits in the vertical chain almost equally (compare $\Pi_{i t}\left(x_{1}, x_{2}\right)$ with $\pi_{i t}\left(x_{1}, x_{2}\right)$ right after Lemma 1 ). Remark 2 Here, we examine the effect of an increase in $\beta_{i}(i=1,2)$. In the duopoly situation, the larger $\beta_{1}$ is, the higher $w_{1 t}$ is, reducing the competitiveness of $D_{1}$ in the downstream market. Here, $U_{1}$ in group 1 is able to overcome the weakness by choosing a location that is closer to the center, although this location accelerates the downstream competition. Because group $i$ anticipates this strong downstream competition, $w_{1 t}$ is determined at a lower level than when $D_{1}$ locates far from the center. Under the assumption that firms' locations are restricted within the line segment, the competition-accelerating effect dominates the demand expansion. ${ }^{12}$

\footnotetext{
12 If firms' locations are not restricted within the line segment, a higher $\beta_{1}$ works as a commitment to
} 
Remark 3 The larger $\beta_{2}$ is, the higher $w_{2 t}$ is, enhancing the competitiveness of $D_{1}$ in the downstream market. However, this competitive advantage is diminished if $U_{1}$ chooses a location closer to the center, because this location accelerates the downstream competition, inducing group 2 to set a lower $w_{2 t}$. The larger $\beta_{2}$ is, the greater the wholesale price reduction is, which implies that $x_{1}$ decreases.

Substituting the results of Equations (8) to (11) into Equations (2) to (5), the total profits of the upstream and the downstream firms in both groups are derived as follows:

$$
\begin{aligned}
V_{1}\left(T_{2}, x_{1}, x_{2}\right) & \equiv V_{1}\left(T_{2}, x_{1}, x_{2}, \tilde{p}_{1 t}\left(x_{1}, x_{2}\right), \tilde{p}_{2 t}\left(x_{1}, x_{2}\right), \tilde{w}_{1 t}\left(x_{1}, x_{2}\right), \tilde{w}_{2 t}\left(x_{1}, x_{2}\right)\right) \\
& =\int_{0}^{T_{2}} \Pi_{1}^{M}\left(x_{1}\right) e^{-(r-\alpha) t} d t+\int_{T_{2}}^{\infty} \Pi_{1}^{D}\left(x_{1}, x_{2}\right) e^{-(r-\alpha) t} d t \\
v_{1}\left(T_{2}, x_{1}, x_{2}\right) & \equiv v_{1}\left(T_{2}, x_{1}, x_{2}, \tilde{p}_{1 t}\left(x_{1}, x_{2}\right), \tilde{p}_{2 t}\left(x_{1}, x_{2}\right), \tilde{w}_{1 t}\left(x_{1}, x_{2}\right), \tilde{w}_{2 t}\left(x_{1}, x_{2}\right)\right) \\
& =\int_{T_{2}}^{\infty} \pi_{1}^{D}\left(x_{1}, x_{2}\right) e^{-(r-\alpha) t} d t-F_{1}, \\
V_{2}\left(T_{2}, x_{1}, x_{2}\right) & \equiv V_{2}\left(T_{2}, x_{1}, x_{2}, \tilde{p}_{1 t}\left(x_{1}, x_{2}\right), \tilde{p}_{2 t}\left(x_{1}, x_{2}\right), \tilde{w}_{1 t}\left(x_{1}, x_{2}\right), \tilde{w}_{2 t}\left(x_{1}, x_{2}\right)\right) \\
& =\int_{T_{2}}^{\infty} \Pi_{2}^{D}\left(x_{1}, x_{2}\right) e^{-(r-\alpha) t} d t, \\
v_{2}\left(T_{2}, x_{1}, x_{2}\right) & \equiv v_{2}\left(T_{2}, x_{1}, x_{2}, \tilde{p}_{1 t}\left(x_{1}, x_{2}\right), \tilde{p}_{2 t}\left(x_{1}, x_{2}\right), \tilde{w}_{1 t}\left(x_{1}, x_{2}\right), \tilde{w}_{2 t}\left(x_{1}, x_{2}\right)\right) \\
& =\int_{T_{2}}^{\infty} \pi_{2}^{D}\left(x_{1}, x_{2}\right) e^{-(r-\alpha) t} d t-F_{2} e^{-r T_{2}} .
\end{aligned}
$$

\subsection{Timing and location of group 2}

Here, we derive the timing and the location outcomes. First, we derive the equilibrium location of group 2. Then, we derive the timing of group 2. In Section 3.3, we derive the equilibrium location of group 1.

First, we derive the equilibrium location of group 2.

locate closer to the center, inducing group 2 to locate outside the line segment. However, the commitment device does not work in the current setting. 
Lemma 3 The upstream firm $U_{2}$ offers location $x_{2}^{E}=1$ in a contract with downstream firm $D_{2}$.

Proof. Differentiating $V_{2}$ with respect to $x_{2}$, we have

$$
\frac{\partial V_{2}}{\partial x_{2}}=\frac{e^{-(r-\alpha) T_{2}} c \beta\left[2\left(4+\beta_{1}\right)-\left(3 x_{2}-x_{1}\right)\left(2-\beta_{1}\right)\right]\left[2\left(4+\beta_{1}\right)-\left(2-\beta_{1}\right)\left(x_{1}+x_{2}\right)\right]}{6(r-\alpha)\left(4-\beta_{1} \beta_{2}\right)^{2}}>0,
$$

implying that $x_{2}^{E}=1$.

This result shows that $x_{2}^{E}=1$ is a dominant strategy for the follower group. The result is the same as that in Ebina et al. (2015), who do not consider the vertical relationship. We show that this result holds for the case with a vertical relationship and for any bargaining power $\beta_{i} \in[0,1]$ with regard to the firms.

Hereafter, to avoid notational clutter, we substitute $x_{2}^{E}=1$ into the equations and omit $x_{2}$ in the third term, where it is not necessary (e.g., $\Pi_{1}^{D}\left(x_{1}, x_{2}^{E}=1\right) \equiv \Pi_{1}^{D}\left(x_{1}\right)$ and $\left.V_{1}\left(T_{2}, x_{1}, x_{2}^{E}=1\right) \equiv V_{1}\left(T_{2}, x_{1}\right)\right)$.

Proposition 1 The equilibrium timing offered by $U_{2}$ to $D_{2}$ is as follows:

$$
\tilde{T}_{2}\left(x_{1}\right)=\frac{1}{\alpha} \log \left[\frac{(r-\alpha) F_{2}}{\pi_{2}^{D}\left(x_{1}\right)}\right]=\frac{1}{\alpha} \log \left[\frac{18\left(4-\beta_{1} \beta_{2}\right)^{2}(r-\alpha) F_{2}}{c\left(2-\beta_{2}\right)^{2}\left(1-x_{1}\right)\left[2\left(3-x_{1}\right)+\left(3+x_{1}\right) \beta_{1}\right]^{2}}\right] .
$$

Proof. First, we show that $V_{2}$ is decreasing in $T_{2}$, as follows:

$$
\frac{\partial V_{2}}{\partial T_{2}}=-\Pi_{2}^{D}\left(x_{1}\right) e^{-(r-\alpha) T_{2}}<0,
$$

which implies that the $U_{2}$ wants $D_{2}$ to enter as soon as possible. Since $U_{2}$ can unilaterally offer $T_{2}$ to $D_{2}, U_{2}$ can induce entry by $D_{2}$ by setting $T_{2}=\tilde{T}_{2}\left(x_{1}\right)$, which satisfies $v_{2}\left(T_{2}, x_{1}\right)=0$. Therefore, we have the following equation:

$$
v_{2}\left(T_{2}, x_{1}\right)=0 \Leftrightarrow \frac{\pi_{2}^{D}\left(x_{1}\right)}{r-\alpha} e^{-(r-\alpha) T_{2}}=F_{2} e^{-r T_{2}} \Leftrightarrow T_{2}=\frac{1}{\alpha} \log \left[\frac{(r-\alpha) F_{2}}{\pi_{2}^{D}\left(x_{1}\right)}\right]\left(\equiv \tilde{T}_{2}\left(x_{1}\right)\right) .
$$

Because $v_{2}$ is negative if and only if $T_{2}<\tilde{T}_{2}\left(x_{1}\right)$, this solution is unique. 
Although the entry timing of group 2 presented in Proposition 1 looks similar to that of Proposition 1 in Ebina et al. (2015), the results are different because of the vertical relationships and the form of competition. We discuss this point in more detail and how this difference affects the equilibrium behavior of the firms in Section 5 .

The following corollaries show the change in group 2's entry timing as the leader's location $x_{1}$ and the exogenous parameters change.

Corollary 1 Given $x_{1}$, the optimal timing of $U_{2}, \tilde{T}_{2}\left(x_{1}\right)$, is decreasing in the bargaining power of $U_{1}, \beta_{1}$, and increasing in that of $U_{2}, \beta_{2}$.

Proof. Differentiating $\tilde{T}_{2}\left(x_{1}\right)$ with respect to $\beta_{1}$ and $\beta_{2}$, we have

$$
\begin{aligned}
& \frac{\partial \tilde{T}_{2}\left(x_{1}\right)}{\partial \beta_{1}}=-\frac{4\left[2\left(3+x_{1}\right)+\beta_{2}\left(3-x_{1}\right)\right]}{\alpha\left(4-\beta_{1} \beta_{2}\right)\left[2\left(3-x_{1}\right)+\beta_{1}\left(3+x_{1}\right)\right]}<0 . \\
& \frac{\partial \tilde{T}_{2}\left(x_{1}\right)}{\partial \beta_{2}}=\frac{4\left(2-\beta_{1}\right)}{\alpha\left(2-\beta_{2}\right)\left(4-\beta_{1} \beta_{2}\right)}>0 .
\end{aligned}
$$

This proves the corollary.

We discuss the intuition behind Corollary 1 . The larger $\beta_{1}$ is, the higher $w_{1 t}$ is, reducing the competitiveness of $D_{1}$ in the downstream market when group 2 stays. This implies that a larger $\beta_{1}$ makes the entry of group 2 easier. The larger $\beta_{2}$ is, the higher $w_{2 t}$ is, enhancing the competitiveness of $D_{1}$ in the downstream market when group 2 exists. This implies that a larger $\beta_{2}$ makes it more difficult for $D_{2}$ to cover its entry cost through its total discounted profit.

Corollary 2 If $x_{1}, F_{2}$, or $r$ increase, or if c or $\alpha$ decrease, the optimal timing of group 2 to enter is delayed. 
Proof. Differentiating $\tilde{T}_{2}\left(x_{1}\right)$ with respect to each parameter, we have

$$
\begin{aligned}
& \frac{\partial \tilde{T}_{2}}{\partial x_{1}}=\frac{10+\beta_{1}\left(1+3 x_{1}\right)-6 x_{1}}{\alpha\left(1-x_{1}\right)\left[6+\beta_{1}\left(3+x_{1}\right)-2 x_{1}\right]}>0, \\
& \frac{\partial \tilde{T}_{2}}{\partial F_{2}}=\frac{1}{\alpha F_{2}}>0, \\
& \frac{\partial \tilde{T}_{2}}{\partial r}=\frac{1}{\alpha(r-\alpha)}>0, \\
& \frac{\partial \tilde{T}_{2}}{\partial c}=-\frac{1}{c \alpha}<0, \\
& \frac{\partial \tilde{T}_{2}}{\partial \alpha}=-\frac{\frac{\alpha}{r-\alpha}+\log \left\{\frac{(r-\alpha) F_{2}}{\pi_{2}^{D}\left(x_{1}\right)}\right\}}{\alpha^{2}}<0 .
\end{aligned}
$$

This proves the corollary.

These properties in Corollary 2, which describe whether each parameter affects the timing of group 2 positively or negatively, are the same as those in Ebina et al. (2015).

Finally, we derive the cross-partial derivatives of $\tilde{T}_{2}\left(x_{1}\right)$ with respect to $\beta_{1}$ or $\beta_{2}$.

Lemma 4 The cross-partial derivatives of $\tilde{T}_{2}$ with respect to $x_{1}$ and $\beta_{i}$ are given as follows:

$$
\begin{aligned}
\frac{\partial^{2} \tilde{T}_{2}}{\partial \beta_{1} \partial x_{1}} & =-\frac{24}{\alpha\left[2\left(3-x_{1}\right)+\beta_{1}\left(3+x_{1}\right)\right]^{2}}<0, \\
\frac{\partial^{2} \tilde{T}_{2}}{\partial \beta_{2} \partial x_{1}} & =0 .
\end{aligned}
$$

We utilize the above lemma to explain how each parameter affects the outcomes in the subgame perfect Nash equilibrium in Subsection 4.2.

\subsection{Location of group 1}

Here, we consider the problem of the leader. Substituting the results of the lemmas and the proposition into Equation (12) of $V_{1}$, we have the following maximization problem for $U_{1}$ :

$$
\begin{aligned}
\max _{x_{1} \in[0,1 / 2]} V_{1}\left(x_{1}\right) & \equiv V_{1}\left(\tilde{T}_{2}\left(x_{1}\right), x_{1}\right) \\
& =\int_{0}^{\tilde{T}_{2}\left(x_{1}\right)} \Pi_{1}^{M}\left(x_{1}\right) e^{-(r-\alpha) t} d t+\int_{\tilde{T}_{2}\left(x_{1}\right)}^{\infty} \Pi_{1}^{D}\left(x_{1}\right) e^{-(r-\alpha) t} d t .
\end{aligned}
$$


In order to obtain the optimal location of $U_{1}$, differentiating $V_{1}$ with respect to $x_{1}$, we have

$$
\begin{aligned}
& \frac{d V_{1}\left(x_{1}\right)}{d x_{1}}=\exp \left(-(r-\alpha) \tilde{T}_{2}\left(x_{1}\right)\right) \frac{d \tilde{T}_{2}\left(x_{1}\right)}{d x_{1}}\left(\Pi_{1}^{M}\left(x_{1}\right)-\right.\left.\Pi_{1}^{D}\left(x_{1}\right)\right) \\
&+\frac{1-\exp \left(-(r-\alpha) \tilde{T}_{2}\left(x_{1}\right)\right)}{r-\alpha} \frac{d \Pi_{1}^{M}\left(x_{1}\right)}{d x_{1}} \\
&+\frac{\exp \left(-(r-\alpha) \tilde{T}_{2}\left(x_{1}\right)\right)}{r-\alpha} \frac{d \Pi_{1}^{D}\left(x_{1}\right)}{d x_{1}} .
\end{aligned}
$$

The sign of Equation (14) is significant and determines the location of group 1 at the center $(1 / 2)$, the edge $(0)$, or an interior point (strictly between 0 and $1 / 2$ ). If the sign of Equation (14) is positive, $U_{1}$ should locate at the center, whereas if it is negative, $U_{1}$ locates at the edge. If Equation (14) is equal to 0 for $x_{1} \in(0,1 / 2), U_{1}$ should locate at the interior point $x_{1}$.

Now, we examine the signs of the three terms in order to obtain the equilibrium location of group 1, and to give economic interpretations of the three terms. The first term of Equation (14) (call it (I), the entry-delay effect) signifies the gain from the delay of entry by group 2 that is caused by an increase in $x_{1}$, allowing group 1 to maintain its monopoly profit before the duopoly regime begins. The sign of the first term is positive, because $\Pi_{1}^{M}\left(x_{1}\right)>\Pi_{1}^{D}\left(x_{1}\right)$ and, thus, the following inequality holds:

$$
\frac{d \tilde{T}_{2}\left(x_{1}\right)}{d x_{1}}=\frac{10+\beta_{1}\left(1+3 x_{1}\right)-6 x_{1}}{\alpha\left(1-x_{1}\right)\left[6+\beta_{1}\left(3+x_{1}\right)-2 x_{1}\right]}>0 .
$$

The second term of Equation (14) (call it (II), the monopoly-gain effect) signifies the increase in the monopoly profit, which is increased by moving closer to the center. As shown below, this term becomes positive:

$$
\frac{d \Pi_{1}^{M}\left(x_{1}\right)}{d x_{1}}=2 c\left(1-x_{1}\right) \beta_{1}>0 .
$$

Finally, the third term of Equation (14) (call it (III), the duopoly-gain effect) signifies how the duopoly profit decreases as group 1 moves closer to group 2, thus intensifying the 
competition. The sign of this term becomes negative:

$$
\frac{d \Pi_{1}^{D}\left(x_{1}\right)}{d x_{1}}=-\frac{c\left(2-\beta_{1}\right) \beta_{1}\left[2+6 x_{1}+\left(5-3 x_{1}\right) \beta_{2}\right]\left[6+2 x_{1}-\left(3-x_{1}\right) \beta_{2}\right]}{6\left(4-\beta_{1} \beta_{2}\right)^{2}}<0 .
$$

Thus, the first and second terms are positive, and the last term is negative. If the effects of (I) and (II) are relatively large, the optimal location of group 1 is $1 / 2$.

We now investigate the effect of each parameter on the equilibrium location of group 1 , $x_{1}^{E}$. If $\tilde{T}_{2}\left(x_{1}\right)$ converges to zero ( $\alpha$ is close to $r$ ), group 2 enters the market immediately, yielding the duopoly competition forever. This implies that $x_{1}^{E}=0$ holds. With regard to the possibility that $x_{1}^{E}=1 / 2$, we have the following proposition.

Proposition 2 (i) If $\bar{u}$ is sufficiently large, $x_{1}^{E}=1 / 2$. (ii) If $\alpha$ is sufficiently small, $x_{1}^{E}=$ $1 / 2$.

Proof. If $\bar{u}$ is sufficiently large, since $\bar{u}$ only exists in the first term being positive, Equation (14) becomes positive.

Related to Equation (14), (15), (16), and (17) and the following inequalities hold:

$$
\begin{aligned}
e^{-(r-\alpha) \tilde{T}_{2}\left(x_{1}\right)} & \geq 0 \\
\Pi_{1}^{M}\left(x_{1}\right)-\Pi_{1}^{D}\left(x_{1}\right) & >\Pi_{1}^{M}(0)-\Pi_{1}^{D}(0) \\
& =\beta_{1}\left[\bar{u}-m+c\left(\frac{3\left(2-\beta_{1}\right)\left(\beta_{2}+2\right)^{2}}{2\left(4-\beta_{1} \beta_{2}\right)^{2}}+1\right)\right]>0, \\
\lim _{\alpha \rightarrow 0} \frac{\exp \left(-(r-\alpha) \tilde{T}_{2}\left(x_{1}\right)\right)}{r-\alpha} & =\lim _{\alpha \rightarrow 0} \frac{\exp \left(-(r-\alpha) \frac{1}{\alpha} \log \left[\frac{(r-\alpha) F_{2}}{\pi_{2}^{D}\left(x_{1}\right)}\right]\right)}{r-\alpha}=0 .
\end{aligned}
$$

Thus, as $\alpha$ approaches 0 , the last terms converge to 0 , whereas the first term becomes positive and infinitely large, and the second term becomes positive and finite. Therefore, when $\alpha$ approaches 0, Equation (14) is positive, implying that the equilibrium location of group 1 is $1 / 2$. 
When $\alpha$ approaches $r$, the timing of group 2's entry becomes earlier, which induces group 1 to weigh the importance of its profitability under the duopoly more highly. ${ }^{13}$ The last term in Equation (14) dominates the other two terms, ${ }^{14}$ which implies that the optimal location of group 1 is $x_{1}^{E}=0$. The relationships between the other parameters, $\beta_{i}, c, r, F_{2}$, and $x_{1}^{E}$ are discussed in Section 4 using a numerical analysis.

\subsection{Outcomes in the subgame perfect Nash equilibrium}

Before we proceed with our numerical analysis, we explicitly show analytical results under two polar cases, where $\alpha$ is sufficiently small, and then sufficiently large. We have the following proposition.

Proposition 3 (i) If Equation (14) is positive, the outcome in the subgame perfect Nash equilibrium is

$$
\begin{aligned}
& T_{2}^{*}=\frac{1}{\alpha} \log \left[\frac{144\left(4-\beta_{1} \beta_{2}\right)^{2} F_{2}(r-\alpha)}{\left(10+7 \beta_{1}\right)^{2}\left(2-\beta_{2}\right)^{2} c}\right], \\
& x_{1}^{*}=\frac{1}{2}, x_{2}^{*}=1, \bar{x}^{*}=\frac{\left(2-\beta_{1}\right)\left(14+5 \beta_{2}\right)}{12\left(4-\beta_{1} \beta_{2}\right)}, \\
& w_{1 t}^{*}=\left\{\begin{array}{l}
w_{1}^{M}\left(x_{1}^{*}\right)=m+\beta_{1}\left(\bar{u}-m-\frac{c}{4}\right) \quad t \in\left[0, T_{2}^{*}\right), \\
w_{1}^{D}\left(x_{1}^{*}\right)=m+\frac{\beta_{1}\left(14+5 \beta_{2}\right) c}{4\left(4-\beta_{1} \beta_{2}\right)} \quad t \in\left[T_{2}^{*}, \infty\right)
\end{array}\right.
\end{aligned}
$$

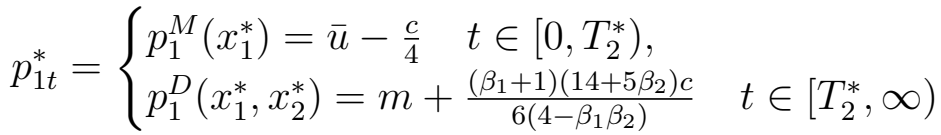

$$
\begin{aligned}
& w_{2 t}^{*}=w_{2}^{D}\left(x_{1}^{*}, x_{2}^{*}\right)=m+\frac{\left(10+7 \beta_{1}\right) \beta_{2} c}{4\left(4-\beta_{1} \beta_{2}\right)} \quad t \in\left[T_{2}^{*}, \infty\right) \\
& p_{2 t}^{*}=p_{2}^{D}\left(x_{1}^{*}, x_{2}^{*}\right)=m+\frac{\left(10+7 \beta_{1}\right)\left(1+\beta_{2}\right) c}{6\left(4-\beta_{1} \beta_{2}\right)} \quad t \in\left[T_{2}^{*}, \infty\right) .
\end{aligned}
$$

\footnotetext{
${ }^{13}$ In contrast to Proposition 2(ii), for higher $\alpha$, we cannot rigorously specify the sign of Equation (14) owing to the upper bound of $\alpha$, which is imposed in Assumption 3(ii). If we could ignore the upper bound of $\alpha$ and could make $\alpha$ approach $r$, we could show that the value in (14) becomes negative.

${ }^{14}$ When $\tilde{T}_{2}$ approaches 0 , the second term of Equation (14) becomes zero.
} 
(ii) If Equation (14) is negative, the outcome in the subgame perfect Nash equilibrium is

$$
\begin{aligned}
& T_{2}^{* *}=\frac{1}{\alpha} \log \left[\frac{2\left(4-\beta_{1} \beta_{2}\right)^{2} F_{2}(r-\alpha)}{\left(2+\beta_{1}\right)^{2}\left(2-\beta_{2}\right)^{2} c}\right], \\
& x_{1}^{* *}=0, x_{2}^{* *}=1, \bar{x}^{* *}=\frac{\left(2-\beta_{1}\right)\left(2+\beta_{2}\right)}{2\left(4-\beta_{1} \beta_{2}\right)} \text {, } \\
& w_{1 t}^{* *}=\left\{\begin{array}{l}
w_{1}^{M}\left(x_{1}^{* *}\right)=m+(\bar{u}-m-c) \beta_{1} \quad t \in\left[0, T_{2}^{* *}\right), \\
w_{1}^{D}\left(x_{1}^{* *}\right)=m+\frac{3 \beta_{1}\left(2+\beta_{2}\right) c}{4-\beta_{1} \beta_{2}} \quad t \in\left[T_{2}^{* *}, \infty\right)
\end{array}\right. \\
& p_{1 t}^{* *}=\left\{\begin{array}{l}
p_{1}^{M}\left(x_{1}^{* *}\right)=\bar{u}-c \quad t \in\left[0, T_{2}^{* *}\right), \\
p_{1}^{D}\left(x_{1}^{* *}, x_{2}^{* *}\right)=m+\frac{2\left(1+\beta_{1}\right)\left(2+\beta_{2}\right) c}{4-\beta_{1} \beta_{2}}
\end{array} \quad t \in\left[T_{2}^{* *}, \infty\right)\right. \\
& w_{2 t}^{* *}=w_{2}^{D}\left(x_{1}^{* *}, x_{2}^{* *}\right)=m+\frac{3\left(2+\beta_{1}\right) \beta_{2} c}{4-\beta_{1} \beta_{2}} \quad t \in\left[T_{2}^{* *}, \infty\right) \\
& p_{2 t}^{* *}=p_{2}^{D}\left(x_{1}^{* *}, x_{2}^{* *}\right)=m+\frac{2\left(2+\beta_{1}\right)\left(1+\beta_{2}\right) c}{4-\beta_{1} \beta_{2}} \quad t \in\left[T_{2}^{* *}, \infty\right) .
\end{aligned}
$$

Proof. Substituting the equilibrium locations, $x_{i}^{E}$, into Equations (8)-(11) of Lemma 1 and Equation (13) of Proposition 1, we have the desired result.

Remark 4 We also obtain an implicit-form solution, as follows. If there exists $\hat{\alpha}$, such that $x_{1}^{* * *}$ is between 0 and $1 / 2$, the outcome in the subgame perfect Nash equilibrium is

$$
\begin{aligned}
& T_{2}^{* * *}=\tilde{T}_{2}\left(x_{1}^{* * *}\right)=\frac{1}{\alpha} \log \left[\frac{18\left(4-\beta_{1} \beta_{2}\right)^{2}(r-\alpha) F_{2}}{c\left(2-\beta_{2}\right)^{2}\left(1-x_{1}^{* * *}\right)\left[2\left(3-x_{1}^{* * *}\right)+\left(3+x_{1}^{* * *}\right) \beta_{1}\right]^{2}}\right], \\
& x_{1}^{* * *} \in(0,1 / 2), x_{2}^{* * *}=1, \bar{x}^{* * *}=\frac{\left(2-\beta_{1}\right)\left[3\left(2+\beta_{2}\right)+\left(2-\beta_{2}\right) x_{1}^{* * *}\right]}{6\left(4-\beta_{1} \beta_{2}\right)}, \\
& w_{1 t}^{* *}= \begin{cases}w_{1}^{M}\left(x_{1}^{* * *}\right)=\left[\bar{u}-c\left(1-x_{1}^{* * *}\right)^{2}\right] \beta_{1}+m\left(1-\beta_{1}\right) & t \in\left[0, T_{2}^{* * *}\right), \\
w_{1}^{D}\left(x_{1}^{* * *}\right)=m+\frac{c \beta_{1}\left(1-x_{1}^{* * *}\right)\left[2\left(3+x_{1}^{* * *}\right)+\left(3-x_{1}^{* * *}\right) \beta_{2}\right]}{4-\beta_{1} \beta_{2}} & t \in\left[T_{2}^{* * *}, \infty\right),\end{cases} \\
& p_{1 t}^{* *}=\left\{\begin{array}{l}
p_{1}^{M}\left(x_{1}^{* * *}\right)=\bar{u}-c\left(1-x_{1}^{* * *}\right)^{2} \quad t \in\left[0, T_{2}^{* * *}\right), \\
p_{1}^{D}\left(x_{1}^{* * *}, x_{2}^{* * *}\right)=m+\frac{2 c\left(1+\beta_{1}\right)\left(1-x_{1}^{* * *}\right)\left[2\left(3+x_{1}^{* * *}\right)+\left(3-x_{1}^{* * *}\right) \beta_{2}\right]}{3\left(4-\beta_{1} \beta_{2}\right)} \quad t \in\left[T_{2}^{* * *}, \infty\right),
\end{array}\right. \\
& w_{2 t}^{* * *}=w_{2}^{D}\left(x_{1}^{* * *}, x_{2}^{* * *}\right)=m+\frac{c \beta_{2}\left(1-x_{1}^{* * *}\right)\left[2\left(3-x_{1}^{* * *}\right)+\left(3+x_{1}^{* * *}\right) \beta_{1}\right]}{4-\beta_{1} \beta_{2}} \quad t \in\left[T_{2}^{* * *}, \infty\right), \\
& p_{2 t}^{* * *}=p_{2}^{D}\left(x_{1}^{* * *}, x_{2}^{* * *}\right)=m+\frac{2 c\left(1+\beta_{2}\right)\left(1-x_{1}^{* * *}\right)\left[2\left(3-x_{1}^{* * *}\right)+\left(3+x_{1}^{* * *}\right) \beta_{1}\right]}{3\left(4-\beta_{1} \beta_{2}\right)} \quad t \in\left[T_{2}^{* * *}, \infty\right) .
\end{aligned}
$$

As shown above, the equilibrium prices, locations, and entry timing depend on the parameters, $c, r, \bar{u}, F_{2}, \alpha$, and $\beta_{i}$. In addition, the above-mentioned outcomes are complicated. We 
confirm how these outcomes change using a numerical analysis, shown in Table 4 in Section 4 .

\section{Numerical analysis}

To investigate the optimal location of group 1 and the total discounted values of the firms, we conduct numerical analyses in Sections 4.1 and 4.2. First, Section 4.1 investigates the effects of the parameters $\bar{u}$ (each consumer's gross surplus for the product), $c$ (consumer's transport cost), $\alpha$ (the growth rate of the market size), $r$ (the interest rate), and $F_{2}$ (group 2's entry cost) on group 1's equilibrium location, denoted as $x_{1}^{E} \in\left\{x_{1}^{*}, x_{1}^{* *}, x_{1}^{* * *}\right\}$. Then, Section 4.2 investigates the effects of the bargaining power, $\beta_{i}$, on $x_{1}^{E}$. In particular, we show that a non-monotonic relationship exists between $\beta_{1}$ and $x_{1}^{E}$.

\subsection{The Effects of $c, m, r, \bar{u}, F_{2}$, and $\alpha$ on $x_{1}^{E}$}

Before discussing the effects of the suppliers' bargaining power $\beta_{i}$, which are the most im-

portant factors in our model, we summarize the effects of $c, m, r, \bar{u}, F_{2}$, and $\alpha$ on $x_{1}^{E}$ by considering Equation (14). The fundamental properties behind the effects of $c, m, r, \bar{u}, F_{2}$, and $\alpha$ on $x_{1}$ are the same as those demonstrated by Ebina et al. (2015).

With regard to $\bar{u}, r$, and $F_{2}$, if one of these parameters increases, group 1 weighs the importance of the monopoly phase more highly, yielding higher $x_{1}^{E}$. Intuitively, an increase in $\bar{u}$ increases only the profit of group 1 in the monopoly phase. Both an increase in $r$ and in $F_{2}$ delay entry by group 2 by increasing its real entry cost, implying a longer duration of the monopoly phase.

With regard to $c$ and $\alpha$, if one of these parameters increases, group 1 weighs the duopoly phase more highly, because such an increase makes entry by group 2 easier as a result of the greater product differentiation between $D_{1}$ and $D_{2}$ and the faster market growth. 
Changing these parameters affects $x_{1}^{E}$. The fundamental direction of these effects is summarized in Table 1

\begin{tabular}{|c||c|c|c|c|c|}
\hline & $c \nearrow$ & $r \nearrow$ & $\bar{u} \nearrow$ & $F_{2} \nearrow$ & $\alpha \nearrow$ \\
\hline \hline$x_{1}^{E}$ & $\searrow$ & $\nearrow$ & $\nearrow$ & $\nearrow$ & $\searrow$ \\
\hline$x_{2}^{E}$ & 1 & 1 & 1 & 1 & 1 \\
\hline
\end{tabular}

Table 1: Locations of firms 1 and 2, when $c, r, \bar{u}, F_{2}$, or $\alpha$ increases. $x_{1}^{E} \nearrow$ means the location of firm 1 approaches 0.5 (the center), whereas $x_{1}^{E} \searrow$ means the location of firm 1 approaches 0 (the edge).

\subsection{The effects of $\beta_{1}$ and $\beta_{2}$ on $x_{1}^{E}$}

We illustrate the relationship between the bargaining powers, $\beta_{1}$ and $\beta_{2}$, and the equilibrium location of group $1, x_{1}^{E}$, in the case where $\bar{u}=25$ (see Table 2 ).

\begin{tabular}{|c||c|c|c|c|c|c|c|c|c|}
\hline$\beta_{1} \backslash \beta_{2}$ & 0.05 & 0.1 & 0.15 & 0.2 & 0.25 & 0.3 & 0.35 & $\cdots$ & 1 \\
\hline \hline 0.1 & 0.5 & 0.5 & 0.259 & 0.140 & 0.035 & 0 & 0 & $\cdots$ & 0 \\
\hline 0.2 & 0.5 & 0.5 & 0.283 & 0.149 & 0.039 & 0 & 0 & $\cdots$ & 0 \\
\hline 0.3 & 0.5 & 0.5 & 0.336 & 0.167 & 0.048 & 0 & 0 & $\cdots$ & 0 \\
\hline 0.4 & 0.5 & 0.5 & 0.5 & 0.197 & 0.063 & 0 & 0 & $\cdots$ & 0 \\
\hline 0.5 & 0.5 & 0.5 & 0.5 & 0.251 & 0.088 & 0 & 0 & $\cdots$ & 0 \\
\hline 0.6 & 0.5 & 0.5 & 0.5 & 0.5 & 0.128 & 0 & 0 & $\cdots$ & 0 \\
\hline 0.7 & 0.5 & 0.5 & 0.5 & 0.5 & 0.198 & 0.019 & 0 & $\cdots$ & 0 \\
\hline 0.8 & 0.5 & 0.5 & 0.5 & 0.5 & 0.5 & 0.074 & 0 & $\cdots$ & 0 \\
\hline 0.9 & 0.5 & 0.5 & 0.5 & 0.5 & 0.5 & 0.5 & 0 & $\cdots$ & 0 \\
\hline
\end{tabular}

Table 2: The equilibrium location $x_{1}^{E}$ for $F_{2}=1000, c=1, m=1, r=0.1, \bar{u}=25$, $\alpha=0.0988$, when $\beta_{1} \in(0,21 / 23)$ and $\beta_{2} \in[0,1]$.

First, we consider how $\beta_{2}$ affects $x_{1}^{E}$. Table 2 shows that as the bargaining power of $U_{2}, \beta_{2}$, increases, the optimal location of group $1, x_{1}^{E}$, monotonically decreases for given $\beta_{1}$. The reason has already mentioned in Remark 3; that is, accelerating the downstream competition through an increase in $x_{1}$ substantially decreases $w_{2 t}$, which is higher owing to 
larger $\beta_{2}$. Thus, $x_{1}$ becomes lower when $\beta_{2}$ is larger. The inverse relation between $\beta_{2}$ and $x_{1}^{E}$ holds on most of the parameter space $\left(c, m, r, \bar{u}, F_{2}, \alpha\right)$.

Second, we consider how $\beta_{1}$ affects $x_{1}^{E}$. As in the decomposition in (14), the location decision of group 1 depends on three effects: (I) the entry-delay effect, (II) the monopoly-gain effect; and (III) the duopoly-gain effect. From (I), the center $\left(x_{1}^{E}=1 / 2\right)$ is the best option and the edge $\left(x_{1}^{E}=0\right)$ is the worst option. This is because the ex post stronger competition, achieved by a central location of $D_{1}$, reduces the profitability of group 2, inducing group 2 to delay its entry. This effect is multiplied by the difference between the profits under the monopoly and the duopoly, $\Pi_{1}^{M}\left(x_{1}\right)-\Pi_{1}^{D}\left(x_{1}\right)$. The higher $\beta_{1}$ is, the stronger the factor is, because an increase in $\beta_{1}$ increases $\Pi_{1}^{M}\left(x_{1}\right)$ directly, owing to the stronger bargaining power, and diminishes $\Pi_{1}^{D}\left(x_{1}\right)$ owing to the weaker competitiveness of group $1 .{ }^{15}$ From (II), the center is the best option and the edge is the worst option, because the monopoly price is constrained by the transportation cost of the furthest consumer from $D_{1}$, and $x_{1}=1 / 2$ minimizes this cost. As in (I), the higher $\beta_{1}$ is, the stronger the factor is. ${ }^{16}$ From (III), the edge is the best option and the center is the worst option, as in the standard spatial competition. The higher $\beta_{1}$ is, the weaker the competitiveness of group 1 is, inducing group 1 to locate closer to the edge. ${ }^{17}$ If the effects of (I) and (II) dominate that of (III), an increase in $\beta_{1}$ induces group 1 to locate closer to the center, as in Table 2.

Note that the monotonic relation between $\beta_{1}$ and $x_{1}^{E}$ does not always hold. To understand

15 Note that, from Lemma 4, the higher $\beta_{1}$ is, the lower $d \tilde{T}_{2}\left(x_{1}\right) / d x_{1}$ is, because a higher $\beta_{1}$ leads to a higher $w_{1}$, which eases the barrier to entry for group 2 . This effect is not that strong, because an increase in $\beta_{1}$ indirectly influences group 2's timing decision through the strategic interaction in the downstream market.

16 Note that an increase in $\beta_{1}$ diminishes the first fraction of the second term in (14) through a decrease in $\tilde{T}_{2}\left(x_{1}\right)$, which diminishes the second term. In the subsequent numerical example, this decrease is offset by the enhancement mentioned in the main text.

17 Note that an increase in $\beta_{1}$ increases the first fraction of the third term in (14) through a decrease in $\tilde{T}_{2}\left(x_{1}\right)$, which increases the absolute value of the third term. 
the complexity of the relation between $\beta_{1}$ and $x_{1}^{E}$, we investigate the relative sizes of the three terms in Equation (14). Using the parameters and group 1's location $x_{1}^{E}$, we derive concrete values of Equation (14) for $\beta_{1} \in(0,0.9]$. The common parameter values are $c=1$, $m=1, r=0.1, \bar{u}=25, F_{2}=1000, \alpha=0.0982$, and $\beta_{2}=0.5$. The result is summarized in Table 3. The "Sum" column in Table 3 indicates how $U_{1}$ decides its location. If the value in the column is negative, then $U_{1}$ locates at 0 . However, if the value is positive, then $U_{1}$ locates at $1 / 2$. If the value is 0 , an interior location between 0 and $1 / 2$ arises. As discussed earlier, each term in Table 3 monotonically changes with an increase in $\beta_{1}$, except for the change between $\beta_{1}=0.45$ and $\beta_{1}=0.5$ in the second term (from 12.1 to 10.9). The exception comes from the substantial change of $x_{1}^{E}$, from 0.051 to 0.5 . This table shows an example in which the relation between $\beta_{1}$ and $x_{1}^{E}$ is non-monotonic.

Third, we consider how $\alpha$ and $\beta_{2}$ influence the relationship between $\beta_{1}$ and $x_{1}^{E}$. Suppose that $c=1, m=1, r=0.1, \bar{u}=25$, and $F_{2}=1000$. The three figures in Figure 1 depict how $\alpha$ influences the relation between $\beta_{1}$ and $x_{1}^{E}$ under $\beta_{2}=0.25, \beta_{2}=0.5$, and $\beta_{2}=0.75$. The top inequality in each figure (e.g., $\alpha \leq 0.0986$ in Figure 1(a)) and the bottom inequality in each figure (e.g., $\alpha \geq 0.0991$ in Figure $1(\mathrm{a})$ ) show that $x_{1}^{E}=0.5$ and $x_{1}^{E}=0$ become the respective equilibrium locations under these ranges of $\alpha$.

Figure 1(a) indicates that as $\alpha$ increases (decreases, respectively), $x_{1}^{E}$ becomes closer to the edge (center, respectively). This result, which is explained in the previous section, is the same as shown in Ebina et al. (2015). As $\alpha$ increases, the duopoly phase becomes longer, inducing group 1 to locate closer to the edge. On the other hand, as $\alpha$ decreases, the monopoly phase becomes longer, inducing group 1 to locate closer to the center. When $\beta_{2}=0.25$ in Figure $1(\mathrm{a}), x_{1}^{E}$ is increasing with $\beta_{1}$. In contrast, when $\beta_{2}=0.5$ and $\beta_{2}=0.75$ in Figures 1(b) and 1(c), respectively, $x_{1}^{E}$ is not always increasing with $\beta_{1}$. Figures $1(\mathrm{~b})$ and 1(c) show an interesting property that the equilibrium location becomes U-shaped with 


\begin{tabular}{|c||c||c|c|c||c|}
\hline$\beta_{1}$ & $x_{1}^{E}$ & (I) First term & (II) Second term & (III) Third term & Sum \\
\hline \hline 0.0001 & 0.5 & 0.0623 & 0.00289 & -0.0611 & 0.00407 \\
\hline 0.05 & 0.5 & 30.7 & 1.41 & -30.2 & 1.88 \\
\hline 0.1 & 0.090 & 37.4 & 3.43 & -40.8 & 0 \\
\hline 0.15 & 0.072 & 54.3 & 4.99 & -59.3 & 0 \\
\hline 0.2 & 0.059 & 70.4 & 6.45 & -76.8 & 0 \\
\hline 0.25 & 0.050 & 85.9 & 7.79 & -93.7 & 0 \\
\hline 0.3 & 0.044 & 101 & 9.02 & -110 & 0 \\
\hline 0.35 & 0.043 & 116 & 10.1 & -126 & 0 \\
\hline 0.4 & 0.044 & 131 & 11.2 & -142 & 0 \\
\hline 0.45 & 0.051 & 146 & 12.1 & -158 & 0 \\
\hline 0.5 & 0.5 & 277 & 10.9 & -264 & 23.5 \\
\hline 0.55 & 0.5 & 302 & 11.6 & -285 & 28.3 \\
\hline 0.6 & 0.5 & 326 & 12.3 & -305 & 34.1 \\
\hline 0.65 & 0.5 & 351 & 13.0 & -323 & 41.0 \\
\hline 0.7 & 0.5 & 375 & 13.5 & -340 & 48.5 \\
\hline 0.75 & 0.5 & 399 & 14.1 & -355 & 57.3 \\
\hline 0.8 & 0.5 & 422 & 14.5 & -369 & 67.4 \\
\hline 0.85 & 0.5 & 446 & 15.0 & -382 & 78.8 \\
\hline 0.9 & 0.5 & 469 & 15.3 & -393 & 91.7 \\
\hline
\end{tabular}

Table 3: Values of the three terms in Equation (14) when $c=1, m=1, r=0.1, \bar{u}=25$, $F_{2}=1000, \alpha=0.0982$, and $\beta_{2}=0.5$.

respect to $\beta_{1}$. In particular, with regard to Figure $1(\mathrm{~b}), x_{1}^{E}$ is in the range $(0,1 / 2)$ if $\beta_{1}$ is neither small nor large; otherwise, $x_{1}^{E}$ is 0 or $1 / 2$. Because there is no clear-cut relation between $\beta_{1}$ and the three significant effects (I), (II), and (III), a non-monotonic relationship between $\beta_{1}$ and $x_{1}^{E}$ can emerge, as in Table 3 .

From the three figures in Figure 1, we determine how $\beta_{2}$ influences the curve of $x_{1}$ for each $\alpha$. When $\beta_{2}=0.25, x_{1}^{E}$ is (almost) monotonically increasing with $\beta_{1}$; when $\beta_{2}=0.5$, $x_{1}^{E}$ forms a U-shape with respect to $\beta_{1}$ and reaches the bottom around $\beta_{1} \in[0.25,0.3]$; when $\beta_{2}=0.75, x_{1}^{E}$ suddenly changes from one corner solution to the other, and reaches the bottom around $\beta_{1} \in[0.45,0.65]$.

It may seem that the discussion in this subsection implies that a manufacturer that needs 

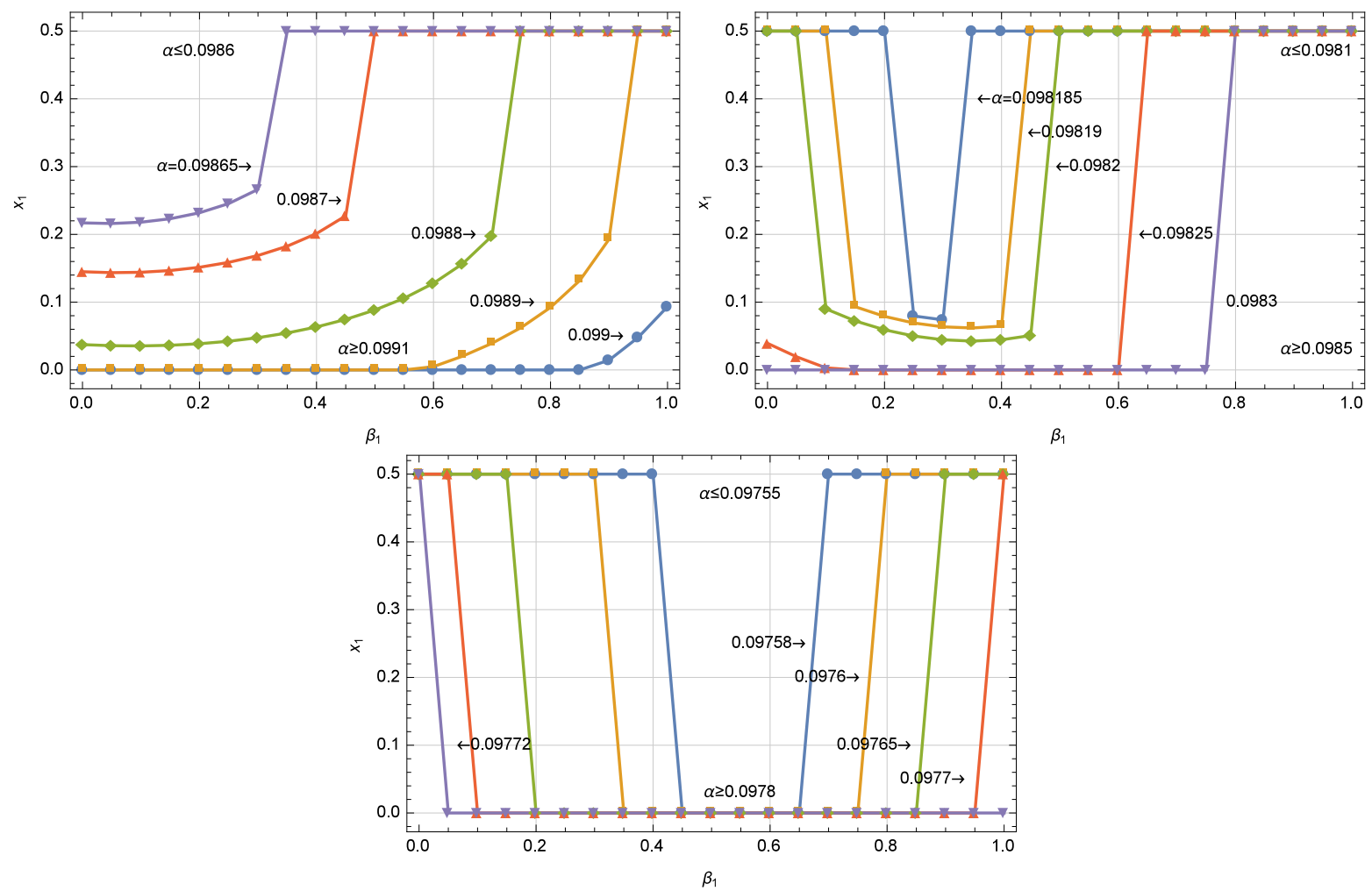

Figure 1: The relationship between $\beta_{1} \in(0,21 / 23)$ and $x_{1}^{E}$, when (a) $\beta_{2}=0.25$ (upper left), (b) $\beta_{2}=0.5$ (upper right), and (c) $\beta_{2}=0.75$ (bottom).

a downstream agent to launch a new product faces a difficulty in determining its optimal product position if it anticipates the subsequent entry of another supplier, and the market growth rate $\alpha$ is close to the interest rate $r$ (if these do not hold, the optimal location is the center of the Hotelling line). However, we do not think that the non-monotonic relationship between $\beta_{1}$ and $x_{1}^{E}$ is a serious problem for $U_{1}$. In other words, we do not think that the significant jump of $x_{1}^{E}$ as a result of an increase in $\beta_{1}$ makes $U_{1}$ difficult to choose its optimal location. In fact, under the parameter set in Figure 2, which is explained later, $V_{1}$ has two locally maximum points with respect to $x_{1}$, and this multiplicity of locally optimal points causes the substantial jump of $x_{1}^{E}$ from one of the two to the other. Thus, as shown in Figure 2 later, $V_{1}$ smoothly changes with $\beta_{1}$, even when $x_{1}$ jumps substantially from one of 
the locally optimal points to another as a result of an increase in $\beta_{1}$. Therefore, the complex relation between $\beta_{1}$ and $x_{1}^{E}$ is not that serious for $U_{1}$, but would be serious for $U_{2}$, as shown in Figure 2, later.

\subsection{The effect of $\beta_{1}$ on $\tilde{T}_{2}\left(x_{1}^{E}\right)$}

Table 4 shows a non-monotonic relationship between $\beta_{1}$ and $\tilde{T}_{2}\left(x_{1}^{E}\right)$ through a monotonic increase in $x_{1}^{E}$. An increase in $\beta_{1}$ has two contrasting effects. First, increasing $\beta_{1}$ itself decreases $\tilde{T}_{2}\left(x_{1}\right)$ for a fixed $x_{1}$, as shown in Corollary 1 . Second, increasing $\beta_{1}$ makes $x_{1}^{E}$ closer to the center, yielding an increase in $\tilde{T}_{2}\left(x_{1}^{E}\right)$ through stronger duopoly competition. We explain the two contrasting effects here using Table 4 . When $\beta_{1} \in(0,0.5]$, the former effect dominates the latter effect; $\tilde{T}_{2}\left(x_{1}^{E}\right)$ decreases, because $x_{1}^{E}$ moves toward the center slowly in accordance with an increase in $\beta_{1}$. In contrast, when $\beta_{1} \in[0.5,0.7]$, the movement of $x_{1}^{E}$ accelerates, so that the latter effect dominates the former effect; $\tilde{T}_{2}\left(x_{1}^{E}\right)$ increases. Moreover, when $\beta_{1} \in[0.7,21 / 23)$, this trend suddenly changes, because $x_{1}^{E}$ reaches $1 / 2$ (the center), and the latter effects vanish. This is why $\tilde{T}_{2}\left(x_{1}^{E}\right)$ decreases again when $\beta_{1} \in[0.7,21 / 23)$.

\begin{tabular}{|c|c||c|c|c|c|c|c|c|c|c|}
\hline$\beta_{2}$ & $\beta_{1}$ & $x_{1}^{E}$ & $x_{2}^{E}$ & $T_{2}^{E}$ & $p_{1}^{M}$ & $w_{1}^{M}$ & $p_{1}^{D}$ & $w_{1}^{D}$ & $p_{2}^{D}$ & $w_{2}^{D}$ \\
\hline \hline 0.1 & 0.001 & 0.120 & 1 & 10.1 & 24.2 & 1.02 & 1.96 & 1.00 & 1.93 & 1.13 \\
\hline 0.1 & 0.1 & 0.126 & 1 & 9.14 & 24.2 & 3.32 & 2.05 & 1.14 & 1.97 & 1.13 \\
\hline 0.1 & 0.2 & 0.136 & 1 & 8.26 & 24.3 & 5.65 & 2.14 & 1.28 & 2.01 & 1.14 \\
\hline 0.1 & 0.3 & 0.153 & 1 & 7.52 & 24.3 & 7.98 & 2.22 & 1.42 & 2.04 & 1.14 \\
\hline 0.1 & 0.4 & 0.178 & 1 & 6.94 & 24.3 & 10.3 & 2.29 & 1.55 & 2.05 & 1.14 \\
\hline 0.1 & 0.5 & 0.215 & 1 & 6.60 & 24.4 & 12.7 & 2.33 & 1.67 & 2.05 & 1.14 \\
\hline 0.1 & 0.6 & 0.276 & 1 & 6.72 & 24.5 & 15.1 & 2.34 & 1.75 & 2.00 & 1.14 \\
\hline 0.1 & 0.7 & 0.5 & 1 & 10.3 & 24.8 & 17.6 & 2.05 & 1.65 & 1.70 & 1.09 \\
\hline 0.1 & 0.8 & 0.5 & 1 & 9.33 & 24.8 & 20 & 2.11 & 1.74 & 1.73 & 1.10 \\
\hline 0.1 & 0.9 & 0.5 & 1 & 8.39 & 24.8 & 22.4 & 2.17 & 1.83 & 1.76 & 1.10 \\
\hline 0.1 & $21 / 23$ & 0.5 & 1 & 8.27 & 24.8 & 22.7 & 2.18 & 1.85 & 1.77 & 1.10 \\
\hline
\end{tabular}

Table 4: The outcome of the subgame perfect Nash equilibrium depending on $\beta_{1}$ and $\beta_{2}$ when $c=1, m=1, r=0.1, \bar{u}=25, F_{2}=1000$, and $\alpha=0.099$. 


\subsection{Effects of bargaining power on the total values}

In this subsection, we investigate how the bargaining power of group $1, \beta_{1}$, affects the total values of the firms $\left(U_{1}, D_{1}, U_{2}\right.$, and $\left.D_{2}\right), V_{1}, v_{1}, V_{2}$, and $v_{2}$. These relationships are summarized in Figure 2. Suppose that $c=1, m=1, r=0.1, \bar{u}=25, F_{1}=0$, and $F_{2}=1000$.
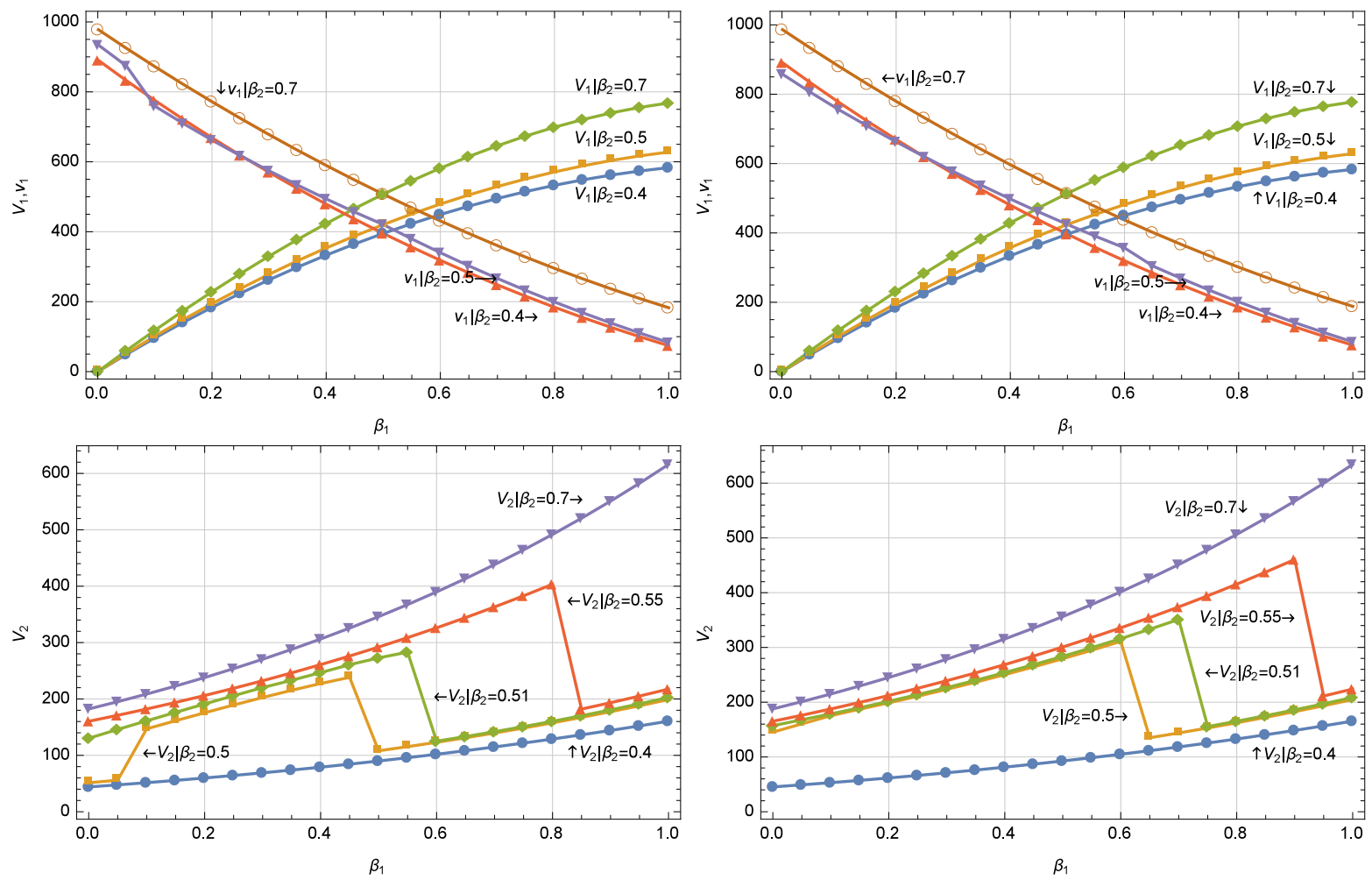

Figure 2: The relationship between $\beta_{1} \in(0,21 / 23)$ and the total values $V_{1}$ and $v_{1}$ in equilibrium when (a) $\alpha=0.0982$ (upper left), and (b) $\alpha=0.09825$ (upper right); and the relationship between $\beta_{1} \in(0,21 / 23)$ and $V_{2}$ in equilibrium when (c) $\alpha=0.0982$ (lower right), and (d) when $\alpha=0.09825$ (lower left).

Figures (a) and (b) in Figure 2 depict the relationship between $\beta_{1}$ and $V_{1}$ and that between $\beta_{1}$ and $v_{1}$ under $\alpha=0.0982$ and $\alpha=0.09825$, respectively. These include the case of $\beta_{2}=0.5$, which is the same as that shown in Figure 1(b). We can easily confirm that the total value of $U_{1}$ strictly increases with $\beta_{1}$, although that of $D_{1}$ strictly decreases with $\beta_{1}$. 
Note that $v_{1}$ drops at some $\beta_{1}$ when $x_{1}^{E}$ changes substantially with an increase in $\beta_{1}$. For example, in Figure 2(a), $\left.v_{1}\right|_{\beta_{2}=0.5}$ drops at $\beta_{1}=0.1$. Furthermore, Figures $2(\mathrm{a})$ and (b) show a non-monotonic relationship between $v_{1}$ and $\beta_{2}$, although the relationship between $V_{1}$ and $\beta_{2}$ is monotonic. With regard to Figure $2(\mathrm{a}),\left.v_{1}\right|_{\beta_{2}=0.4} \geq\left. v_{1}\right|_{\beta_{2}=0.5}$ holds for $\beta_{1} \in[0.1,0.2]$, though $\left.v_{1}\right|_{\beta_{2}=0.4}<\left.v_{1}\right|_{\beta_{2}=0.5}$ holds for $\beta_{1} \in(0,0.1)$ and for $\beta_{1} \in(0.2,21 / 23)$. With regard to Figure 2(b), we see a similar relationship, where $\left.v_{1}\right|_{\beta_{2}=0.4} \geq\left. v_{1}\right|_{\beta_{2}=0.5}$ holds for $\beta_{1} \in(0,0.2]$, though $\left.v_{1}\right|_{\beta_{2}=0.4}<\left.v_{1}\right|_{\beta_{2}=0.5}$ holds for $\beta_{1} \in(0.2,21 / 23)$.

As mentioned in the last paragraph in Section 4.2, the non-monotonic relationship between $x_{1}^{E}$ and $\beta_{1}$ has a significant impact on $U_{2}$. To understand the relation between the non-monotonic relationship and $V_{2}$, we focus on the case of $\alpha=0.0982$ in Figure $1(\mathrm{~b})$ and $\left.V_{2}\right|_{\beta_{2}=0.5}$ in Figure 2(c). When $\alpha=0.0982$ in Figure $1(\mathrm{~b}), x_{1}^{E}$ drops substantially from $1 / 2$ to about 0.1 when $\beta_{1}$ moves from 0.05 to $0.1 ; x_{1}^{E}$ moves around 0.075 when $\beta_{1}$ is in the range $[0.1,0.45]$; and $x_{1}^{E}$ jumps up substantially from about 0.05 to $1 / 2$ when $\beta_{1}$ moves from 0.45 to 0.5. Related to the substantial drop and the substantial jump around $\beta_{1}=0.1$ and $\beta_{1}=0.5$, respectively, $\left.V_{2}\right|_{\beta_{2}=0.5}$ in Figure $2(\mathrm{c})$ jumps significantly at $\beta_{1}=0.1$, and drops significantly at $\beta_{1}=0.5$. Furthermore, for other values of $\beta_{2}$, in Figures $2(\mathrm{c})$ and $(\mathrm{d})$, we observe that $V_{2}$ drops or jumps substantially, which is related to the non-monotonic relationship between $x_{1}^{E}$ and $\beta_{1}$. Therefore, we conclude that the complex relation between $x_{1}^{E}$ and $\beta_{1}$ has a significant impact on $U_{2}$.

\section{Discussion}

We discuss how changing the assumption of $U_{2}$ 's strong position over $D_{2}$ in the entry timing affects our results in Section 5.1. Then, we discuss whether changing from asymmetric to symmetric bargaining power affects our result in Section 5.2. 


\subsection{Difference between this model and the model of Ebina et al. (2015)}

In this subsection, we examine whether changing the assumption of $U_{2}$ 's strong position over $D_{2}$ in the entry timing to reflect that in Ebina et al. (2015) affects our main results.

Before proceeding with the analysis, we briefly check the entry decisions of group 2 (firm 2 ) in this study and those in Ebina et al. (2015). The optimal entry timing of firm 2 (follower) under the setting of Ebina et al. (2015) is

$$
\bar{T}_{2}\left(x_{1}\right)=\frac{1}{\alpha} \log \left[\frac{r F_{2}}{\bar{\pi}_{2}^{D}\left(x_{1}\right)}\right]=\frac{1}{\alpha} \log \left[\frac{18 r F_{2}}{c\left(1-x_{1}\right)\left(3-x_{1}\right)^{2}}\right],
$$

where $\bar{\pi}_{2}^{D}\left(x_{1}\right)=c\left(1-x_{1}\right)\left(3-x_{1}\right)^{2} / 18$ denotes the duopoly profit of firm 2 , whereas the optimal timing of group 2 in our setting is given in Equation (13). There are two differences between the two studies. The first stems from the difference in the duopoly profits, which is based on whether vertical relations exist. This difference in the duopoly profits changes the difference from $\bar{\pi}_{2}\left(x_{1}\right)$ to $\tilde{\pi}_{2}\left(x_{1}\right)$. The second stems from the difference in the criteria for market entry. In Ebina et al. (2015), the follower has the freedom to choose when it enters the market. In contrast, $U_{2}$ maximizes its profit by choosing $T_{2}$, which satisfies the zero-profit condition for $D_{2}$. This difference makes group 2 enter sooner, with the timing changing from $r$ to $r-\alpha$, which corresponds to the numerator inside the logarithm in (13).

Thus, changing the second assumption on the criteria for market entry made in this study to that made in Ebina et al. (2015), we have

$$
\begin{aligned}
& \frac{\partial v_{2}}{\partial T_{2}}=0 \\
\Rightarrow & \hat{T}_{2}\left(x_{1}\right)=\frac{1}{\alpha} \log \left[\frac{r F_{2}}{\tilde{\pi}_{2}^{D}\left(x_{1}\right)}\right]=\frac{1}{\alpha} \log \left[\frac{18\left(4-\beta_{1} \beta_{2}\right)^{2} r F_{2}}{c\left(2-\beta_{2}\right)^{2}\left(1-x_{1}^{* * *}\right)\left[2\left(3-x_{1}^{* * *}\right)+\left(3+x_{1}^{* * *}\right) \beta_{1}\right]^{2}}\right] .
\end{aligned}
$$

Next, we conduct a numerical analysis using the same parameter values in Section 4 . Suppose that $r=0.1, F_{2}=1000, c=1$, and $m=25$, which are the same as in Figures $1(\mathrm{~b})$ 
and (c). When $\beta_{2}=0.5$ and 0.75 , the equilibrium location pattern of group 1 is as shown in Figures 3(a) and (b), respectively.
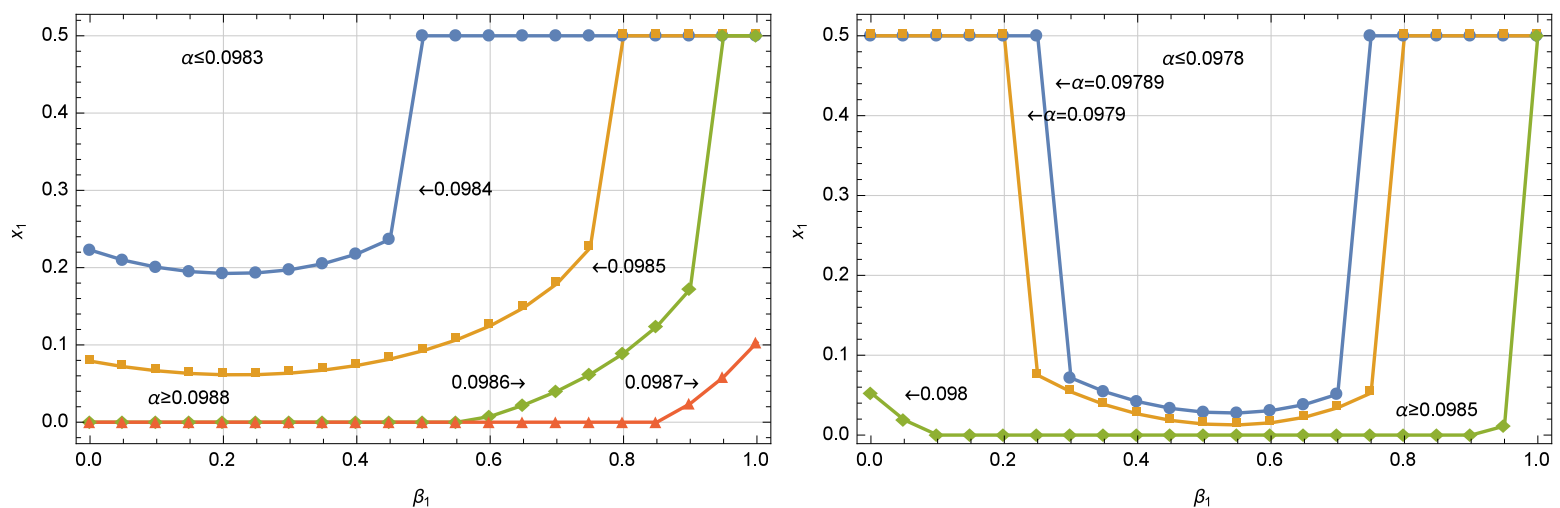

Figure 3: The relationship between the equilibrium location of group 1 and $\beta_{1} \in(0,21 / 23)$ under the setting of Ebina et al. (2015) when (a) $\beta_{2}=0.5$ (left) and (b) $\beta_{2}=0.75$ (right).

Comparing Figures 1(b) and 3(a) (Figures 1(c) and 3(b), respectively), a slight increase in $\beta_{2}$ has a similar impact on $x_{1}^{E}$ in both this study and that of Ebina et al. (2015). ${ }^{18}$ This is because the sign of the first-order derivatives of $\tilde{T}_{2}$ and $\hat{T}_{2}$ with respect to the parameters are the same. Therefore, we verify that the U-shaped nature of $x_{1}^{E}$ on $\beta_{2}$, which is an interesting finding of this study, depends on the vertical relationship, but does not depend on the market entry criteria for the follower.

\subsection{Symmetric bargaining power}

Many studies assume symmetric bargaining power, in the sense that the bargaining powers of all firms are equal $\left(\beta_{1}=\beta_{2}(\equiv \beta)\right)$, and investigate firms' behavior under vertical relationships. ${ }^{19}$ In this subsection, we briefly discuss how employing the assumption of sym-

\footnotetext{
${ }^{18}$ We also conduct a numerical analysis under the setting of Ebina et al. (2015) when $\beta_{2}=0.9$, and obtain a figure that shows a sudden change of $x_{1}^{E}$ from one corner solution to the other corner solution, similarly to Figure 1(c). We omit the figure owing to space limitations.

19 See, for instance, the non-spatial oligopoly model in Horn and Wolinsky (1988).
} 
metric bargaining power affects our main results.

Figure 4(a) depicts the relationship between $\beta$ and $x_{1}^{E}$ when $\alpha$ changes. Suppose that $c=1, m=1, r=0.1, \bar{u}=25$, and $F_{2}=1000$. This setting is the same as that in Figure 1, and the result is summarized in Table 3. In contrast to the asymmetric case shown in Figure 1, where $x_{1}^{E}$ can be increasing or U-shaped, we confirm that $x_{1}^{E}$ is decreasing in $\beta$. This relationship is strong, because the rival's wholesale price reduction owing to the narrower distance between $D_{1}$ and $D_{2}$ is strong. Thus, although many studies consider a Nash bargaining problem under symmetric bargaining in a discrete time model, it is important to consider asymmetric bargaining power when examining a vertical relationship through Nash bargaining by employing a continuous-time model.
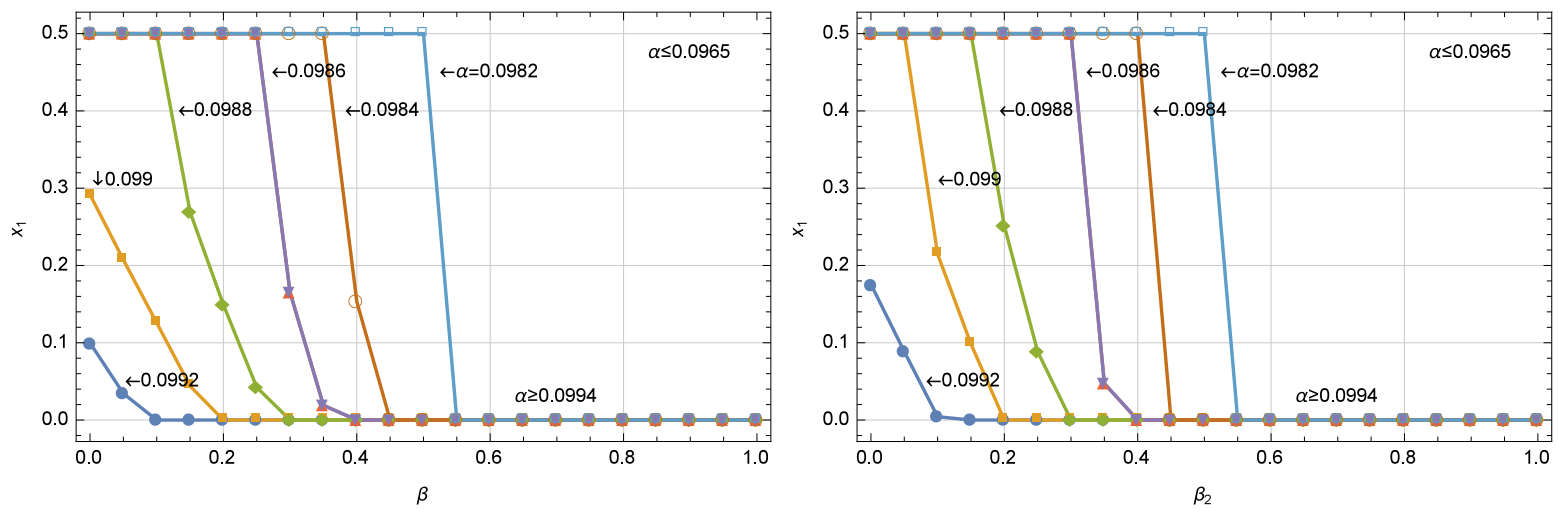

Figure 4: The relationship between (a) the equilibrium location of group 1 and symmetric bargaining power $\beta$ (left) and (b) $x_{1}^{E}$ and the bargaining power of group $2 \beta_{2}$ when $\beta_{1}=0.5$ (right).

Finally, we briefly discuss the relationship between $x_{1}^{E}$ and $\beta_{2}$. Figure $4(\mathrm{~b})$ depicts the relationship between $\beta_{2} \in[0,1)$ and $x_{1}^{E}$ when $\beta_{1}=0.5$. The settings of the other parameters are the same as in the symmetric case. The fundamental shapes of the graphs, which are downward sloping, are similar to the symmetric case, and for the same reason. Thus, we focus only on the relationship between $\beta_{1}$ and $x_{1}^{E}$, and on the values of the firms in the 
previous section.

\section{Conclusion}

This study investigates a dynamic Hotelling duopoly model with endogenous entry timing and location choices under vertical contracting. We focus on how upstream suppliers' bargaining power over their downstream buyers $\left(\beta_{1}\right.$ and $\left.\beta_{2}\right)$ influence the locations $\left(x_{1}\right.$ and $\left.x_{2}\right)$ and the entry timing of the follower pair $\left(T_{2}\right)$. A larger $\beta_{1}$ usually induces a larger $x_{1}$ and, thus, a larger $T_{2}$. This implies that the stronger bargaining power of the supplier can also benefit the downstream buyer; that is, it might be better for a downstream buyer to weaken its bargaining position over its trading supplier. In addition, under some sets of exogenous parameters, there is a non-monotonic relation between $\beta_{1}$ and $x_{1}$. More specifically, the equilibrium location of the leader pair can jump substantially with an increase in $\beta_{1}$, which significantly delays $T_{2}$ and diminishes the profitability of the follower pair. Moreover, a larger $\beta_{2}$ induces a smaller $x_{1}$, which facilitates the earlier entry of the follower pair. This implies that when an upstream manufacturer tries to enter a newly growing market with its downstream representative, it needs to maintain its strong bargaining power over the representative.

This study shows that the bargaining power of an upstream manufacturer/franchiser over a downstream representative/franchisee affects the entry timings and location points. As mentioned in the introduction, several studies emphasize that large national retailers tend to have strong bargaining power over their upstream firms (Geylani et al., 2007; Inderst and Shaffer, 2007, 2009). Our results indicate that location points and entry timings are strongly affected by such bargaining power. Our theoretical results suggest that as the bargaining powers strengthen, the location of group 1 will move closer to an interior, or center (not the edge), and that group 2 will wait longer before entering a new market. 
We assume that the leader immediately enters the market (i.e., $T_{1}=0$ ). As in Ebina et al. (2017), considering the endogenous entry timing of the leader pair is a topic for future research, although it substantially complicates the analysis. In addition, future research can explore a more sophisticated contract term, such as a two-part tariff contract, as in Alpranti et al. (2015).

\section{Appendix}

We explain the condition in which the market is fully covered by $D_{1}$ in the monopoly case. The profit of $D_{1}$ is given as

$$
\pi_{1 t}^{M}\left(x_{1}\right)= \begin{cases}\left(p_{1 t}-w_{1 t}\right) & \text { if } p_{1 t} \leq u-c\left(1-x_{1}\right)^{2}, \\ \left(p_{1 t}-w_{1 t}\right)\left[\sqrt{\frac{u-p_{1 t}}{c}}+x_{1}\right] & \text { if } u-c\left(1-x_{1}\right)^{2}<p_{1 t} \leq u-c x_{1}^{2}, \\ 2\left(p_{1 t}-w_{1 t}\right) \sqrt{\frac{u-p_{1 t}}{c}} & \text { if } u-c x_{1}^{2}<p_{1 t} \leq u .\end{cases}
$$

The first-order condition is given as

$$
\frac{\partial \pi_{1 t}^{M}\left(x_{1}\right)}{\partial p_{1 t}}= \begin{cases}1 & \text { if } p_{1 t} \leq u-c\left(1-x_{1}\right)^{2}, \\ x_{1}+\frac{2 u-3 p_{1 t}+w_{1 t}}{2 \sqrt{c\left(u-p_{1 t}\right)}} & \text { if } u-c\left(1-x_{1}\right)^{2}<p_{1 t} \leq u-c x_{1}^{2}, \\ \frac{2 u-3 p_{1 t}+w_{1 t}}{2 \sqrt{c\left(u-p_{1 t}\right)}} & \text { if } u-c x_{1}^{2}<p_{1 t} \leq u .\end{cases}
$$

We show the condition that the optimal price of $D_{1}$ at each $t \in\left[0, T_{2}\right)$ is $p_{1 t}=u-c(1-$ $\left.x_{1}\right)^{2}$, which is the maximum price among those that lead to full coverage of the market. When $u-c\left(1-x_{1}\right)^{2}<p_{1 t} \leq u-c x_{1}^{2}$, the second-order condition is

$$
\frac{\partial^{2} \pi_{1 t}^{M}\left(x_{1}\right)}{\partial p_{1 t}^{2}}=\frac{-4 u+3 p_{1 t}+w_{1 t}}{4 \sqrt{c}\left(u-p_{1 t}\right) \sqrt{u-p_{1 t}}}(<0) .
$$

Under this range of $p_{1 t}, \pi_{1 t}^{M}\left(x_{1}\right)$ monotonically decreases with $p_{1 t}$ if the following inequality holds:

$$
\left.\frac{\partial \pi_{1 t}^{M}\left(x_{1}\right)}{\partial p_{1 t}}\right|_{\downarrow p_{1}=u-c\left(1-x_{1}\right)^{2}}=1-\frac{u-c\left(1-x_{1}\right)^{2}-w_{1 t}}{2 c\left(1-x_{1}\right)}<0
$$


that is,

$$
w_{1 t}<u-c\left(1-x_{1}\right)\left(3-x_{1}\right)
$$

If $w_{1 t}$ does not satisfy the inequality, this $w_{1 t}$ does not maximize the joint profit in group 1 because the market demand is not fully covered.

When the firms in group 1 anticipate that $D_{1}$ sets $p_{1 t}\left(x_{1}\right)=u-c\left(1-x_{1}\right)^{2}$ in the pricing stage, the bargaining outcome in the negotiation stage is

$$
\beta_{1}: 1-\beta_{1}=\left(w_{1 t}-m\right): u-c\left(1-x_{1}\right)^{2}-w_{1 t} \rightarrow w_{1 t}\left(x_{1}\right)=\beta_{1}\left(u-c\left(1-x_{1}\right)^{2}\right)+\left(1-\beta_{1}\right) m .
$$

If this $w_{1 t}\left(x_{1}\right)$ satisfies the inequality in (19), $D_{1}$ actually sets $p_{1 t}\left(x_{1}\right)=u-c\left(1-x_{1}\right)^{2}$, given $w_{1 t}\left(x_{1}\right)=\beta_{1}\left(u-c\left(1-x_{1}\right)^{2}\right)+\left(1-\beta_{1}\right) m$. Substituting $w_{1 t}$ in (20) into (19), we obtain

$$
c\left(1-x_{1}\right)\left(3-x_{1}-\beta_{1}\left(1-x_{1}\right)\right)<\left(1-\beta_{1}\right)(u-m)
$$

This becomes the most stringent condition when the left-hand side is maximized. For $x_{1} \in$ $[0,1 / 2]$, it is maximized at $x_{1}=0$, and then the condition becomes

$$
c\left(3-\beta_{1}\right)<\left(1-\beta_{1}\right)(u-m) \rightarrow \beta_{1}<\frac{u-m-3 c}{u-m-c} .
$$

\section{References}

Alipranti, M., C. Milliou, E. Petrakis. 2015. On vertical relations and the timing of technology adoption. Journal of Economic Behavior \& Organization 120, 117-129.

Brekke, K.R., O.R. Straume. 2004. Bilateral monopolies and location choice. Regional Science and Urban Economics 34(3), 275-288.

Bronnenberg, B.J., V. Mahajan. 2001. Unobserved retailer behavior in multimarket data: Joint spatial dependence in market shares and promotion variables. Marketing Science 20(3), 284-299.

Chen, Z. 2003. Dominant retailers and the countervailing-power hypothesis. RAND journal of Economics 34(4), 612-625. 
Cleeren, K., F. Verboven, M.G. Dekimpe, K. Gielens. 2010. Intra- and inter-format competition among discounters and supermarkets. Marketing Science 29(3), 456-473.

d'Aspremont, C., J.-J. Gabszewicz, J.-F. Thisse. 1979. On Hotelling's stability in competition. Econometrica 47(5), 1145-1150.

Desai, P.S. 2001. Quality segmentation in spatial markets: When does cannibalization affect product line design? Marketing Science 20(3), 265-283.

Dobson, P.W., M. Waterson. 1997. Countervailing power and consumer prices. Economic Journal 107(441), 418-430.

Draganska, M., M. Mazzeo, K. Seim. 2009. Beyond plain vanilla: Modeling joint product assortment and pricing decisions. Quantitative Marketing and Economics 7(2), 105146.

Dukes, A.J., E. Gal-Or, K. Srinivasan. 2006. Channel bargaining with retailer asymmetry. Journal of Marketing Research 63(1), 84-97.

Ebina, T., N. Matsushima, K. Nishide. 2017. Demand uncertainty, product differentiation, and entry timing under spatial competition. ISER Discussion Paper No.1007. Available at https://ideas.repec.org/p/dpr/wpaper/1007.html

Ebina, T., N. Matsushima, D. Shimizu. 2015. Product differentiation and entry timing in a continuous time spatial competition model. European Journal of Operational Research 247(3), 904-913.

Erkal, N. 2007. Buyer-supplier interaction, asset specificity, and product choice. International Journal of Industrial Organization 25(5), 988-1010.

Geylani, T., A.J. Dukes, K. Srinivasan. 2007. Strategic manufacturer response to a dominant retailer. Marketing Science 26(2), 164-178.

Götz, G. 2005. Endogenous sequential entry in a spatial model revisited. International Journal of Industrial Organization 23(3-4), 249-261.

Hauser, J.R. 1988. Competitive price and positioning strategies. Marketing Science 7(1), 76-91.

Horn, H., A. Wolinsky. 1988. Bilateral monopolies and incentives for merger. RAND Journal of Economics 19(3), 408-419.

Hwang, M., B.J. Bronnenberg, R. Thomadsen. 2010. An empirical analysis of assortment similarities across U.S. supermarkets. Marketing Science 29(5), 858-879.

Inderst, R., G. Shaffer. 2007. Retail mergers, buyer power and product variety. Economic Journal 117(516), 45-67. 
Inderst, R., G. Shaffer. 2009. Market power, price discrimination, and allocative efficiency in intermediate-goods markets. RAND Journal of Economics 40(4), 658-672.

Kim, H., K. Serfes. 2006. A location model with preference for variety. Journal of Industrial Economics 54(4), 569-595.

Kuksov, D. 2004. Buyer search costs and endogenous product design. Marketing Science 23(4), 490-499.

Lambertini, L. 2002. Equilibrium locations in a spatial model with sequential entry in real time. Regional Science and Urban Economics 32(1), 47-58.

Liu, Y., R.K. Tyagi 2011. The benefits of competitive upward channel decentralization. Management Science 57(4), 741-751.

Loertscher, S., G. Muehlheusser. 2011. Sequential location games. RAND Journal of Economics 42(4), 639-663.

Matsumura, T., N. Matsushima. 2009. Cost differentials and mixed strategy equilibria in a Hotelling model. Annals of Regional Science 43(1), 215-234.

Matsushima, N. 2004. Technology of upstream firms and equilibrium product differentiation. International Journal of Industrial Organization 22(8-9), 1091-1114.

Matsushima, N. 2009. Vertical mergers and product differentiation. Journal of Industrial Economics 57(4), 812-834.

Matsushima, N., A. Miyaoka. 2015. The effects of resale-below-cost laws in the presence of a strategic manufacturer. Quantitative Marketing and Economics 13(1), 59-91.

Matsushima, N., C. Pan. 2016. Strategic perils of outsourcing: Sourcing strategy and product positioning. ISER Discussion Paper No. 983.

Available at https://ideas.repec.org/p/dpr/wpaper/0983.html

Moorthy, K.S. 1988. Product and price competition in a duopoly. Marketing Science 7(2), $141-168$.

Muthoo, A. 1999. Bargaining Theory with Applications. Cambridge University Press, Cambridge.

Orhun, A.Y. 2013. Spatial differentiation in the supermarket industry: The role of common information. Quantitative Marketing and Economics 11(1), 3-37.

Peres, R., E. Muller., V. Mahajan. 2010. Innovation diffusion and new product growth models: A critical review and research directions. International Journal of Research in Marketing 27(2), 91-106. 
Raju, J., Z.J. Zhang. 2005. Channel coordination in the presence of a dominant retailer. Marketing Science 24(2), 254-262.

Raynaud, E., L. Saubée, E. Valceschini. 2009. Aligning branding strategies and governance of vertical transactions in agri-food chains. Industrial and Corporate Change 18(5), $835-868$.

Reinartz, W., B. Dellaert, M. Krafft, V. Kumar, R. Varadarajan. 2011. Retailing innovations in a globalizing retail market environment. Journal of Retailing 87(S1), S53-S66.

Sajeesh, S. 2016. Influence of market-level and inter-firm differences in costs on product positioning and pricing. Applied Economics Letters 23(12), 888-896.

Sajeesh, S., J. Raju. 2010. Positioning and pricing in a variety seeking market. Management Science, 56(6), 949-961.

Tabuchi, T., J.-F. Thisse. 1995. Asymmetric equilibria in spatial competition. International Journal of Industrial Organization 13(2), 213-227.

Thomadsen, R. 2007. Product positioning and competition: The role of location in the fast food industry. Marketing Science 26(6), 792-804.

Wernerfelt, B. 1986. Product line rivalry: Note. American Economic Review 76(4), 842844.

Zhu, T., V. Singh. 2009. Spatial competition with endogenous location choices: An application to discount retailing. Quantitative Marketing and Economics 7(1), 1-35. 